Afrika Zamani, No. 5, 1997 and No. 6, 1998

\title{
Religion and Politics in Africa
}

\author{
Stephen Ellis \& Gerrie ter Harr*
}

All religion is based on a belief in the existence of invisible forces Which influence human destiny. So important is belief of this sort in contemporary African thought, we will argue in this essay, that many Africans appear to believe that the widely-attested malaise of their public life may be explained largely, or even primarily, by reference to these invisible forces.

Among the evidence for this assertion is the rapid growth of movements of religious renewal or revival which are to be found in ail parts of Africa today, especially those which are sometimes described as 'fundamentalist', and of new religious movements in general (Tozy 1995:58-74; Gifford 1994:513-34; Mbembe 1988). some of the ideas articulated by and within these movements may be construed as a critique of the way in which power is organized. Drawing on a rich religious imagery, many popular texts circulating in Africa today constitute a commentary on a world in which power is represented as being too often an instrument that evil people use to destroy peace and harmony. To put it in more familiar and more prosaic terms, these texts are an oblique criticism of misgovernment. And like any group of people who come together in search of power, Africa's new religious movements are, themselves a field of action in Which that elusive commodity, power, may be acquired and redistributed.

"In the following pages we will discuss what power is and how it is represented from various points of view before examining the political implications of the growth of new religious movements in Africa.

(2)

\section{Power and Its Organization}

Power is usually defined as the ability of a person to induce others to act in the way which he or she requires (Bullock and Stallybrass

* Stephen Ellis (Afrika-Studiecentrum, Leiden) and Gerrie ter Haar (Catholic

Theological University, Utrecht), Netherlands. 


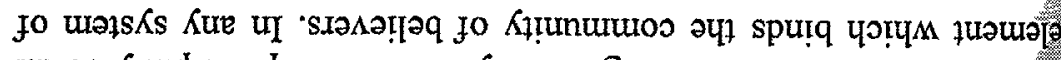

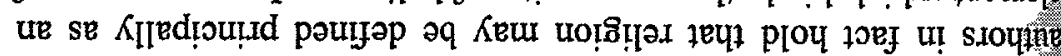

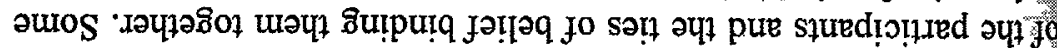

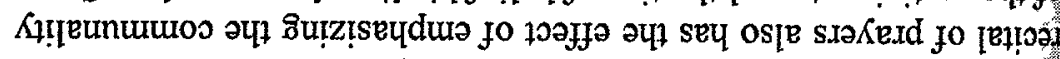

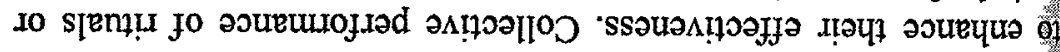

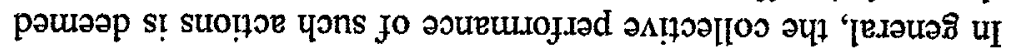

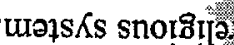

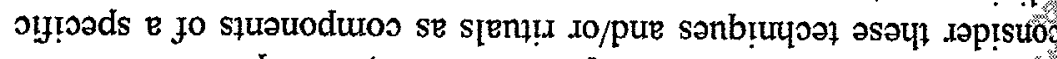

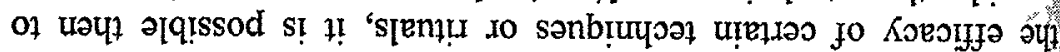

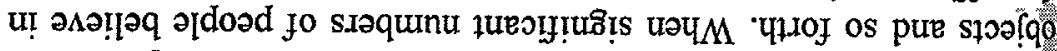

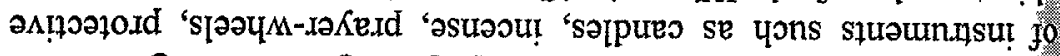

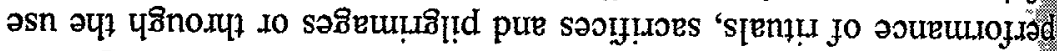

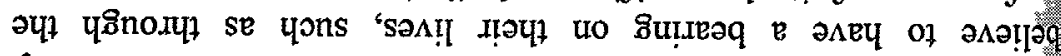

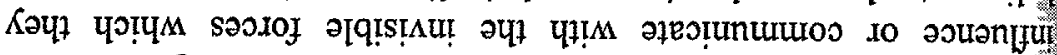

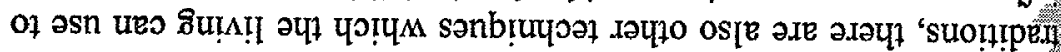

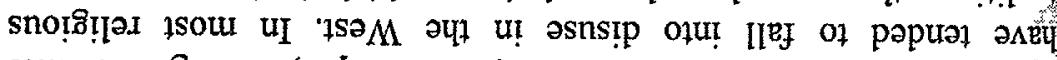

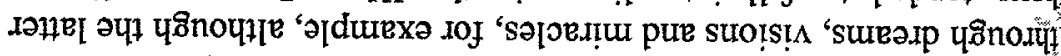

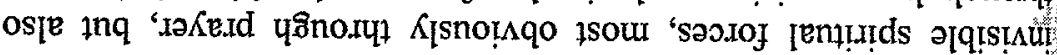

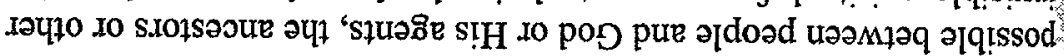

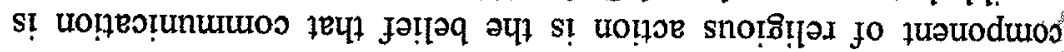

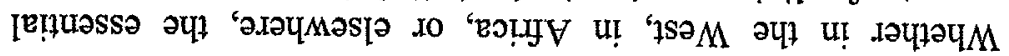

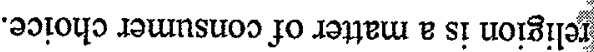

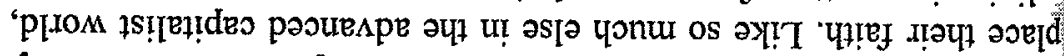

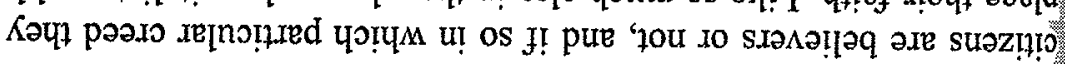

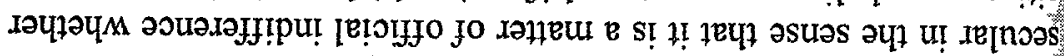

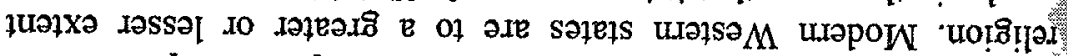

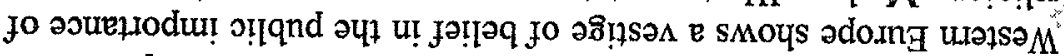

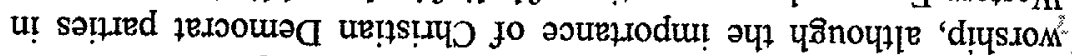

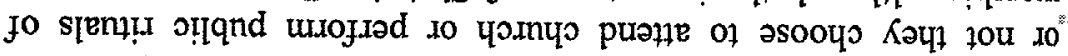

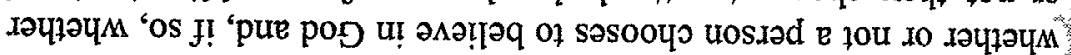

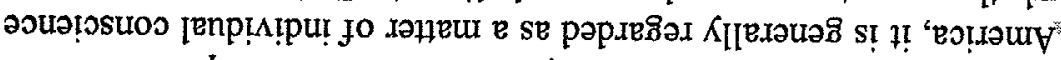

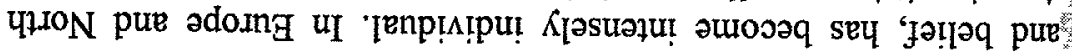

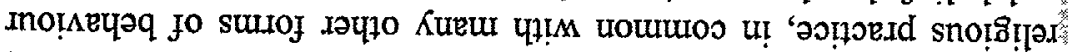

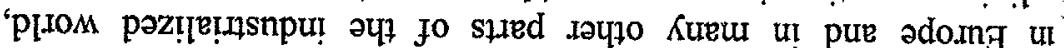

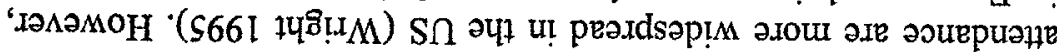

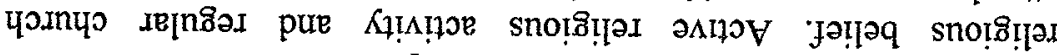

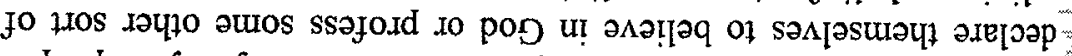

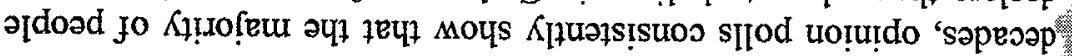

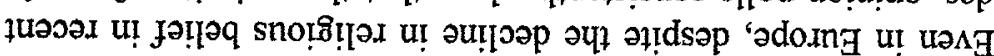

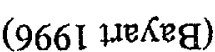

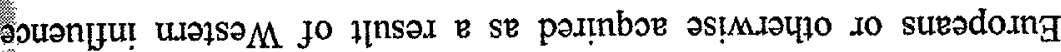

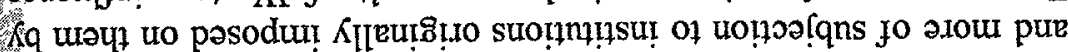

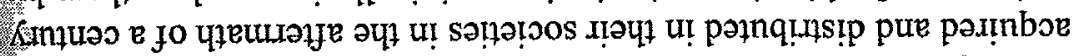

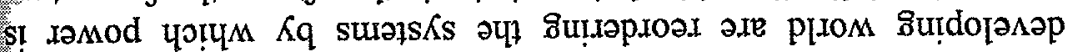

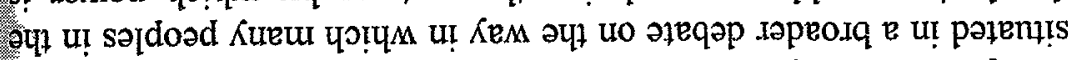

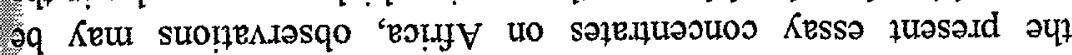

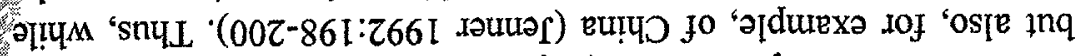

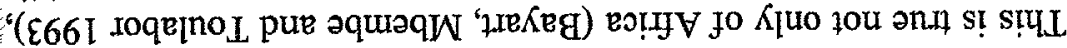

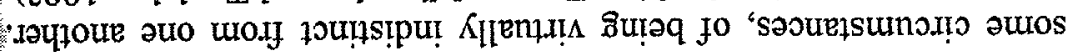

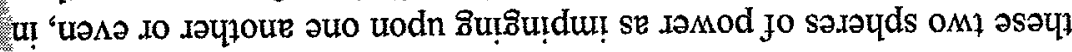

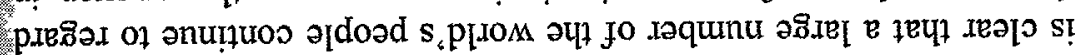

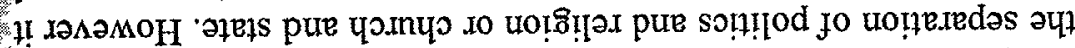

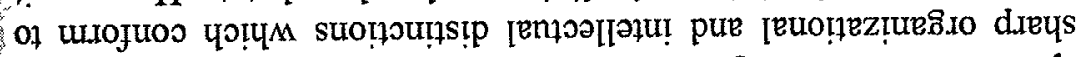

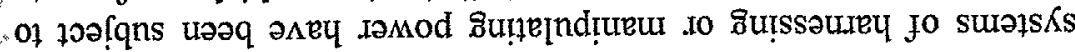

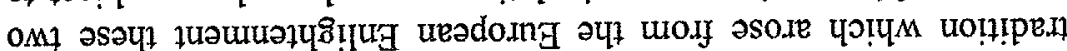

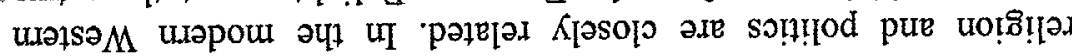

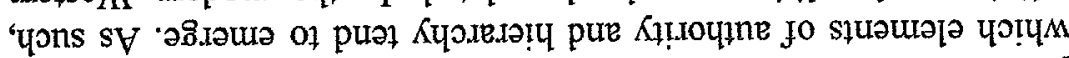

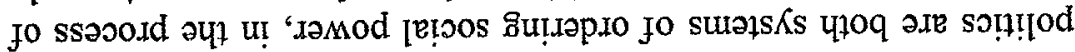

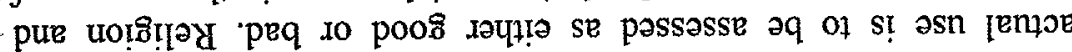

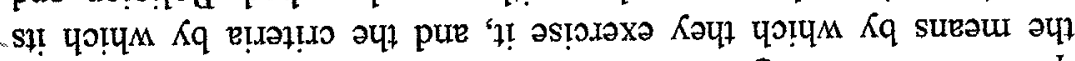

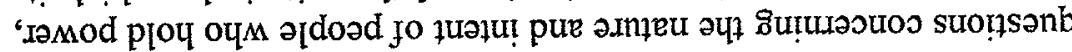

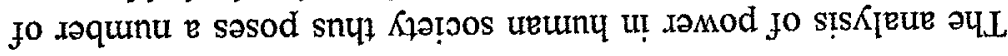

usิ!̣̂u

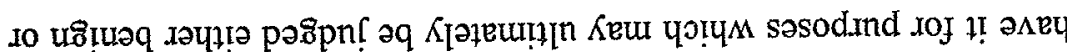

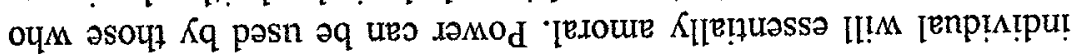

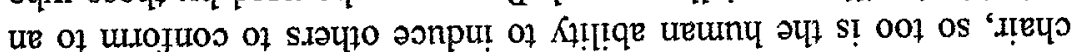

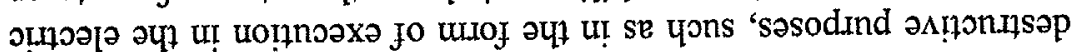

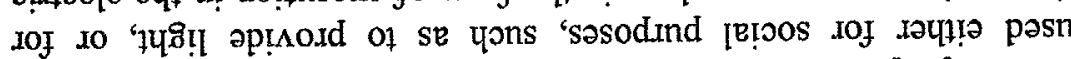

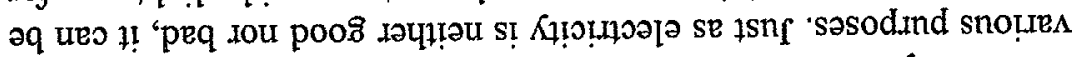

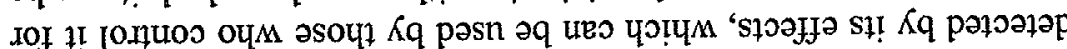

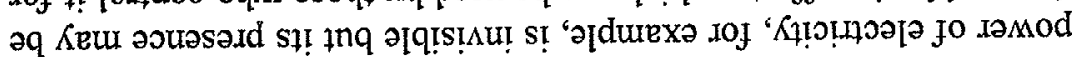

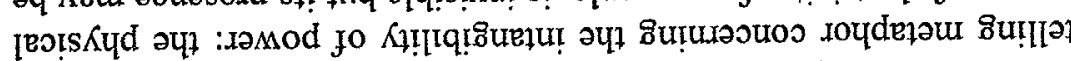

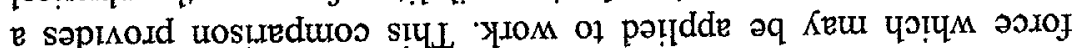

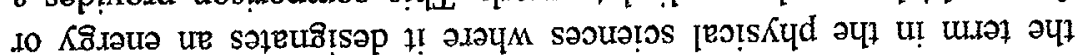

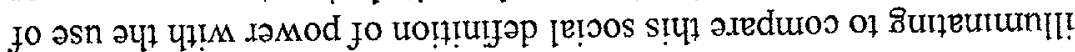

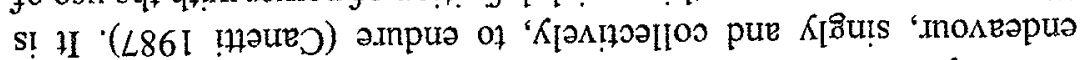

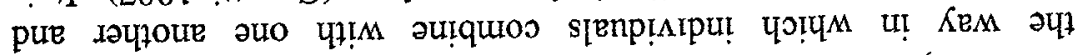

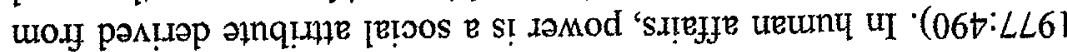




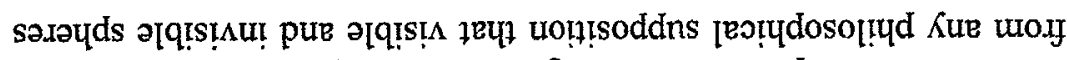

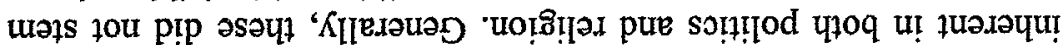
دәмод әчң јо иопредs!

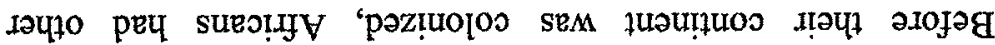

parte әq Keu uoturdo

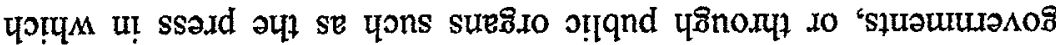
Кq шәу⿰亻⿱

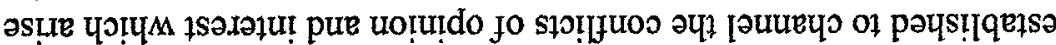

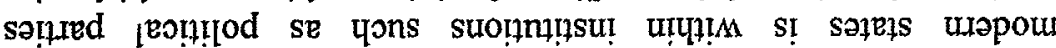
u! Kł!

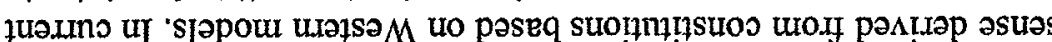

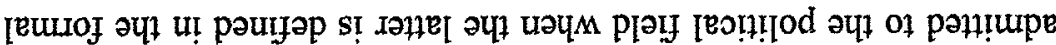

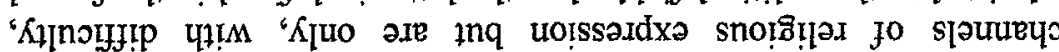

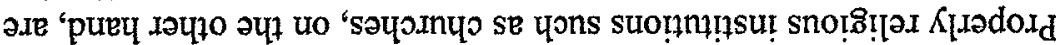

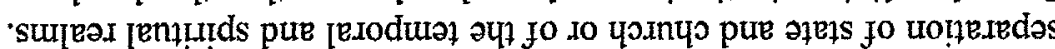

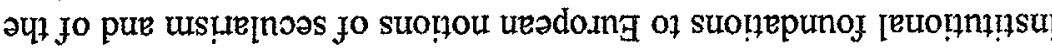

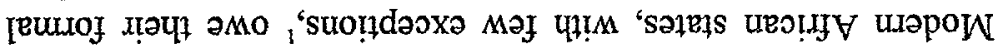

eolig u! xәMod

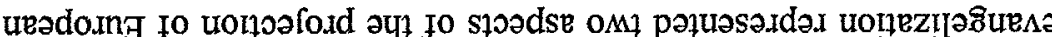

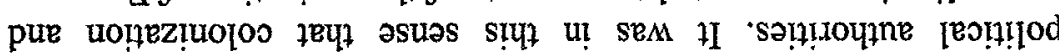

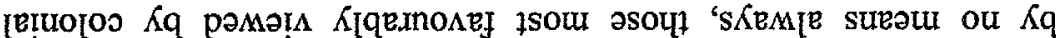

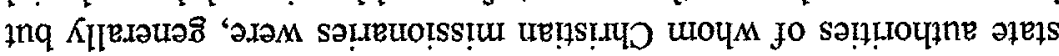

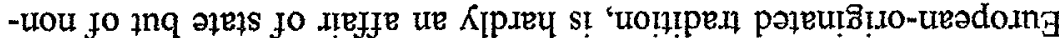

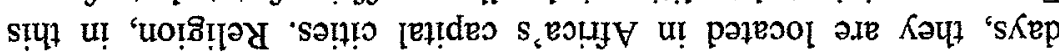

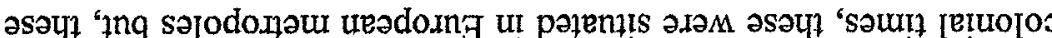
uT 'sa!!!

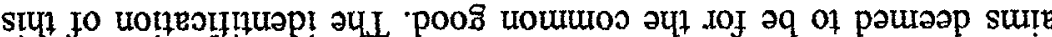

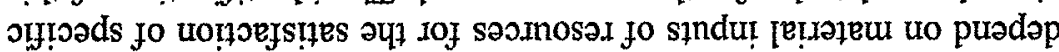

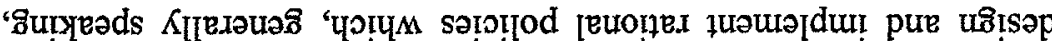
of pure MEl jo wals

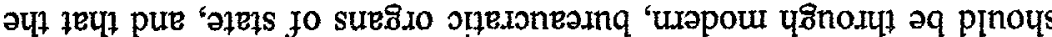

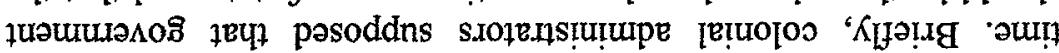

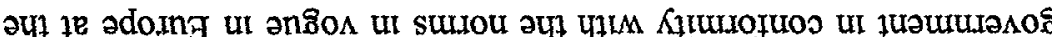

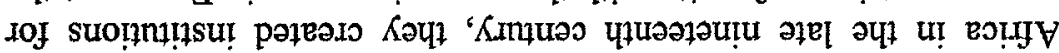

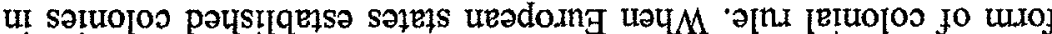

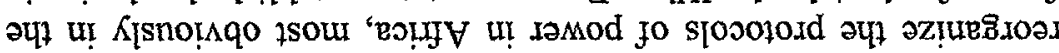

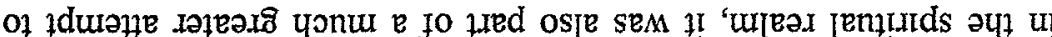

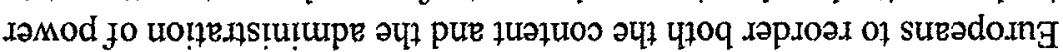

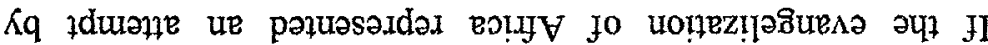

'seltdur

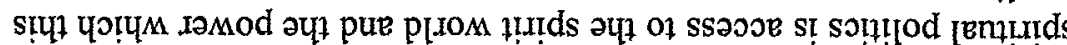

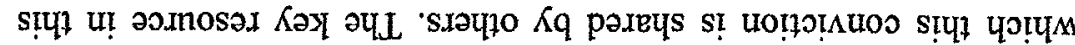

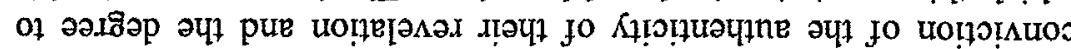

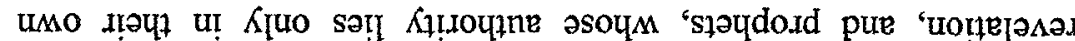

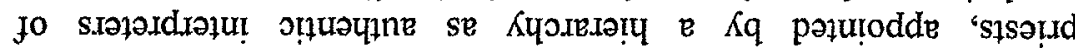

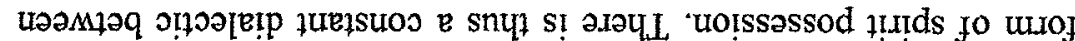

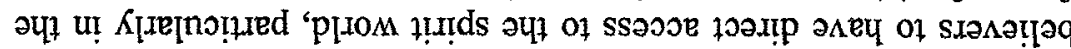

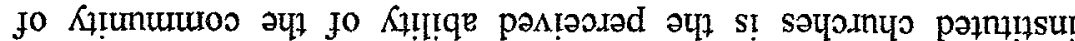

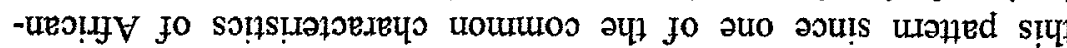

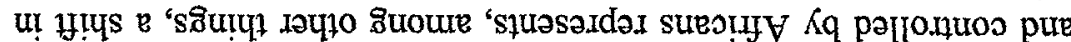

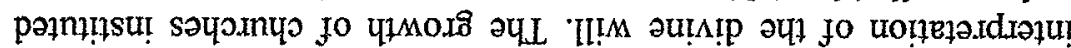

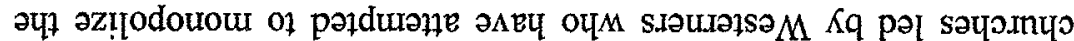

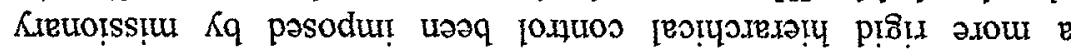

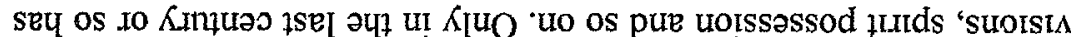

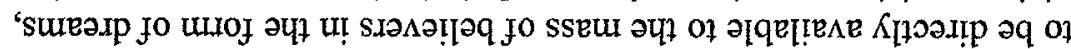

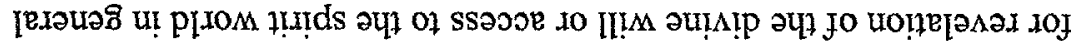
suo!s:

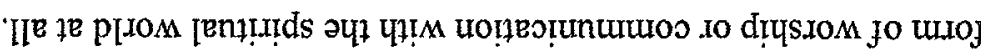

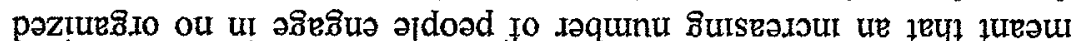

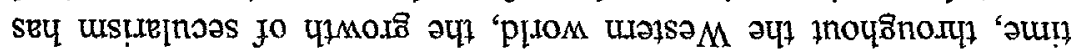

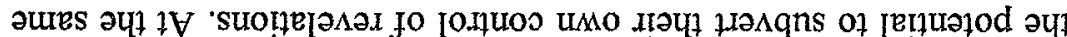

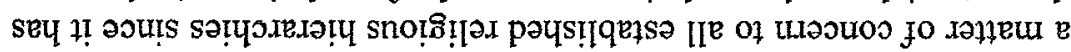

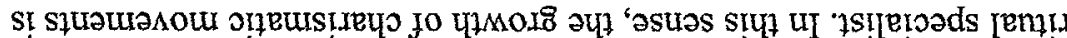

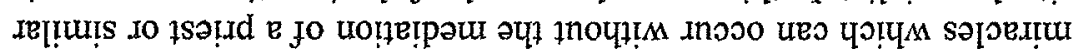

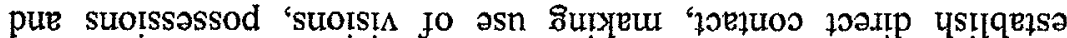

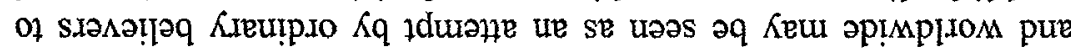

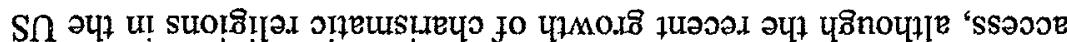

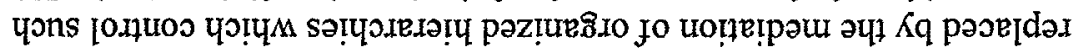

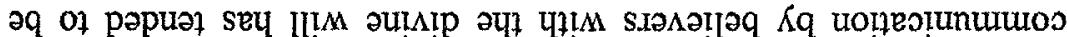

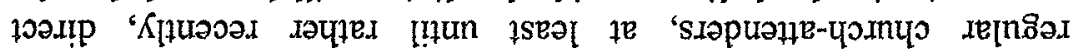

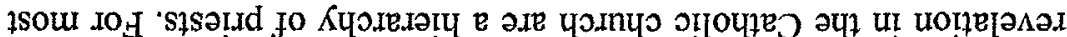

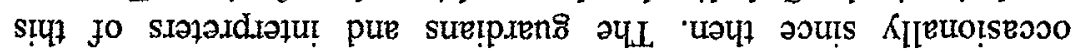

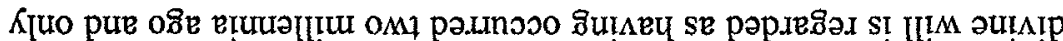

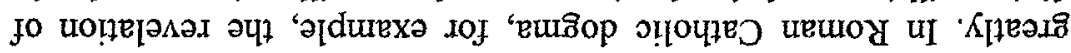

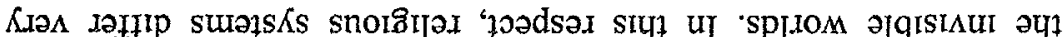

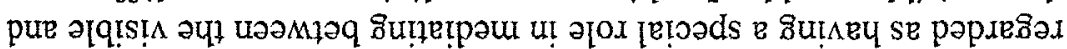

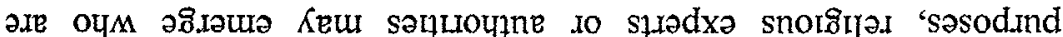

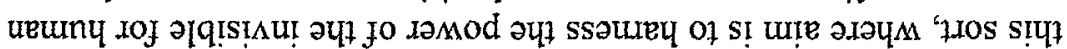




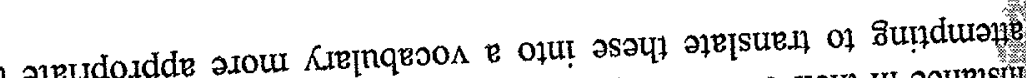

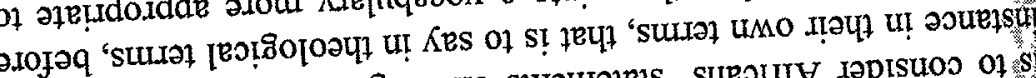

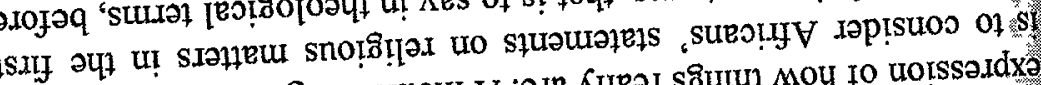

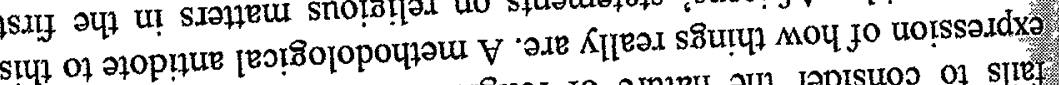

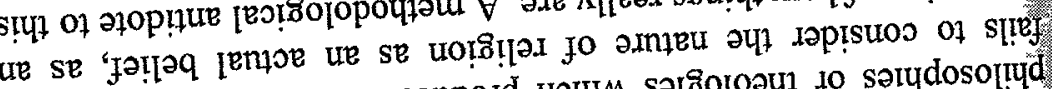

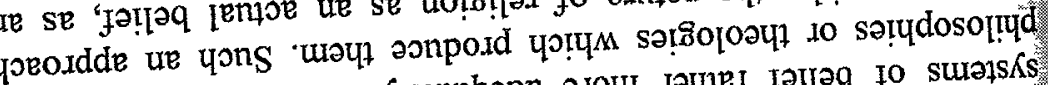

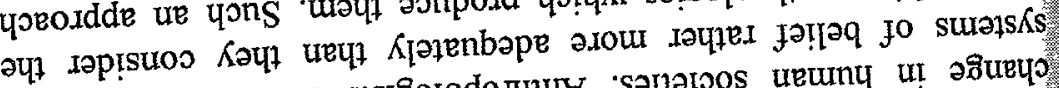

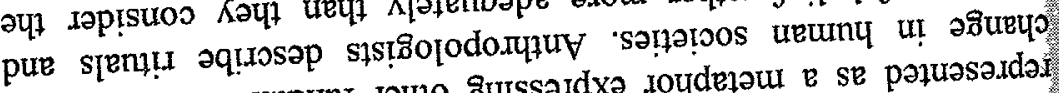

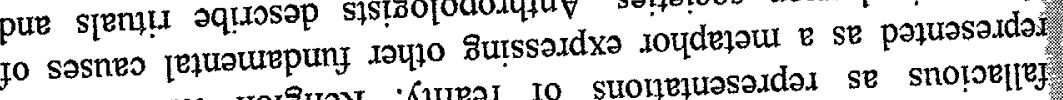

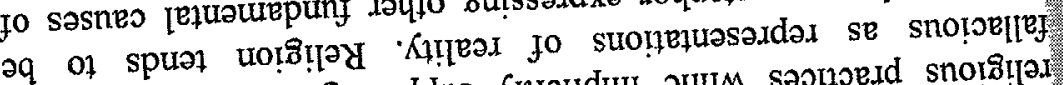

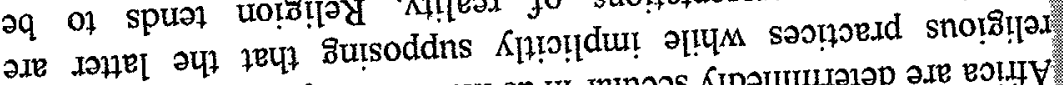

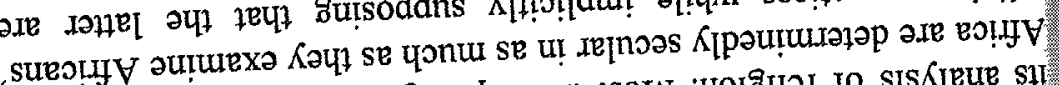

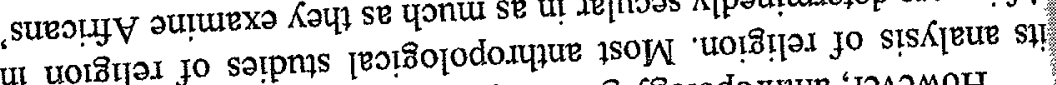

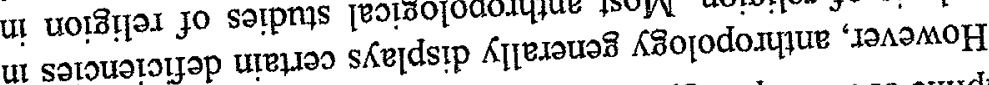

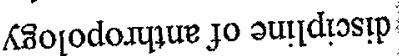

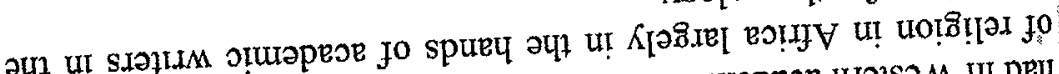

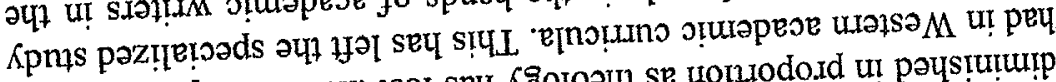

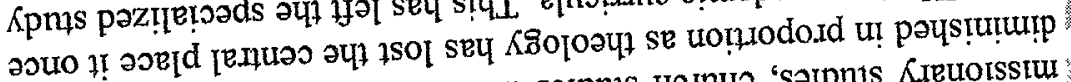

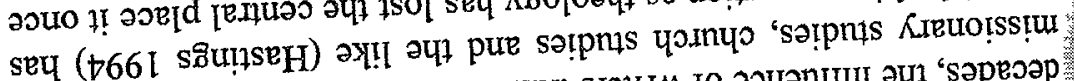

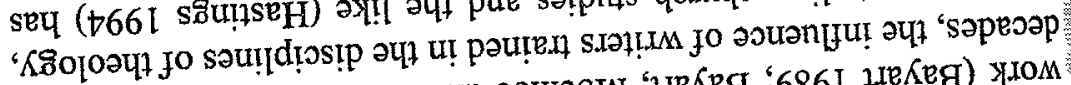

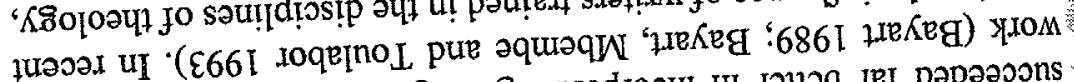

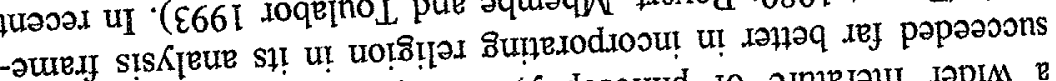

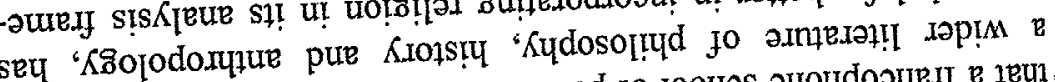

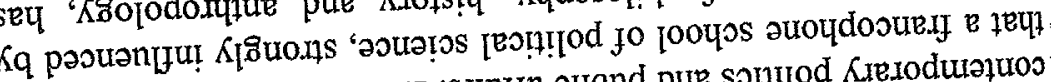

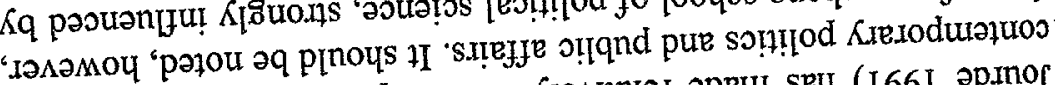

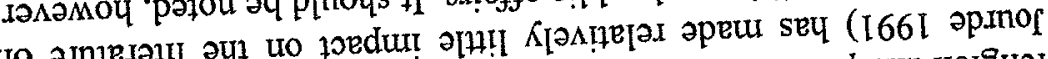

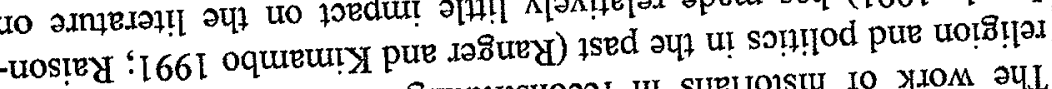

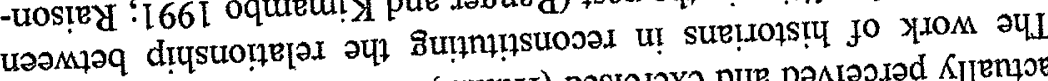

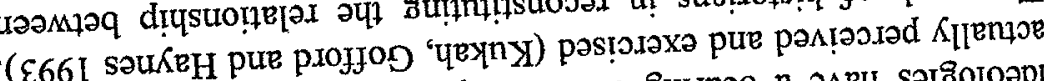

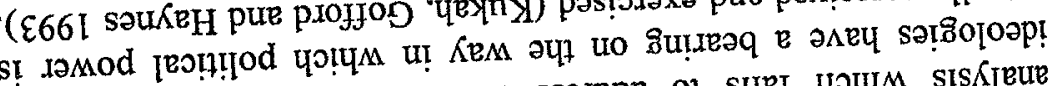

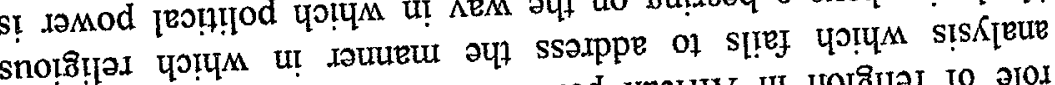

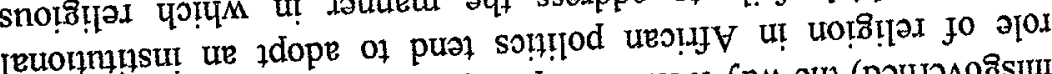

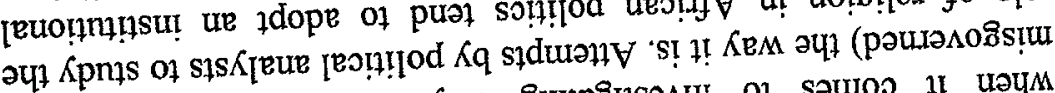

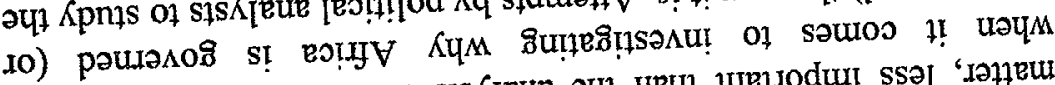

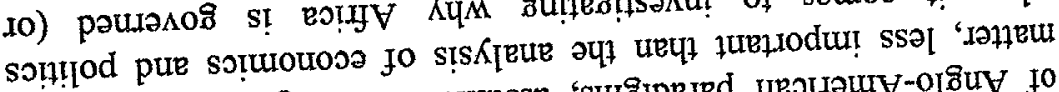
үexnโן

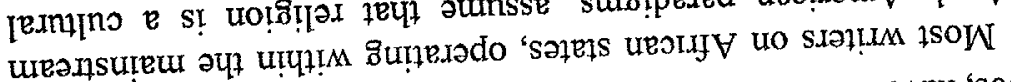

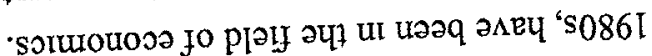

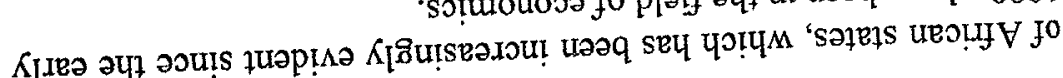

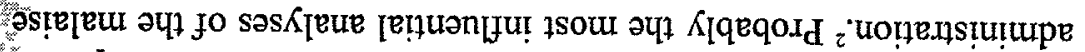

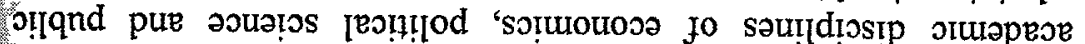

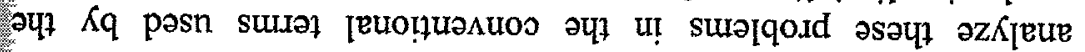

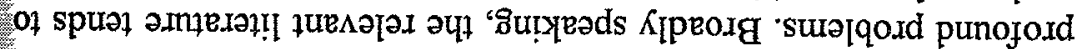

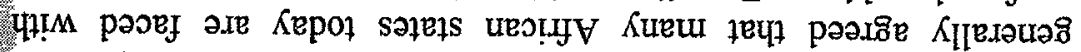

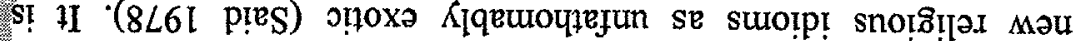
8unฺ

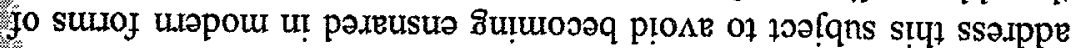

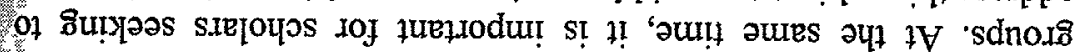

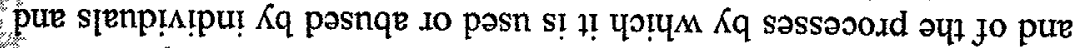

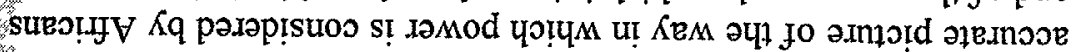

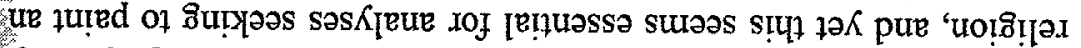

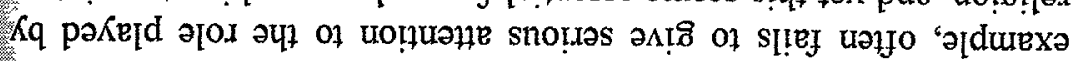

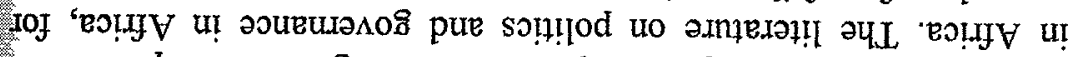

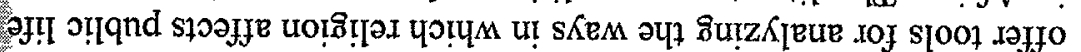

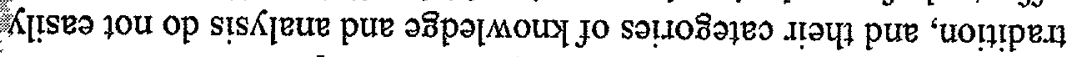

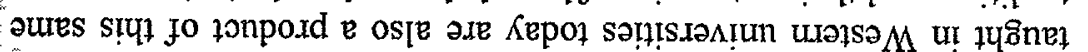

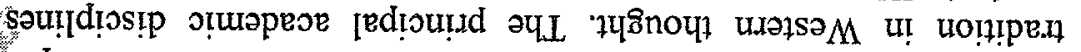

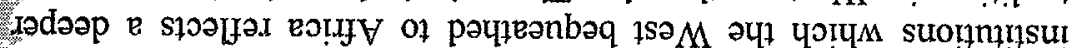

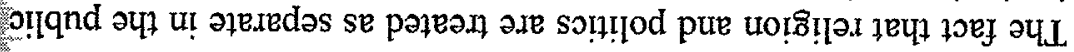

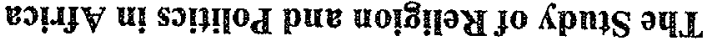

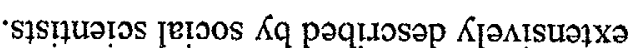

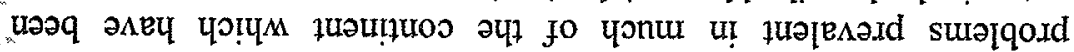
jeo!n! u! suo!̣! sno!̣̣̂!

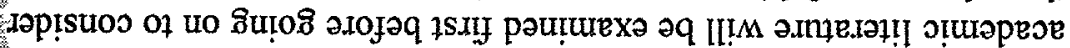

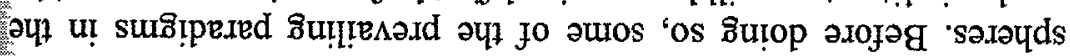

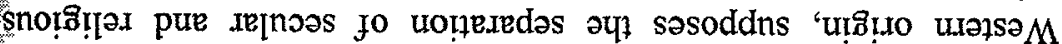

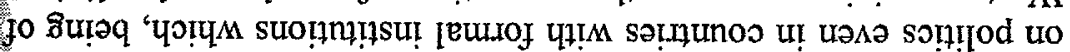

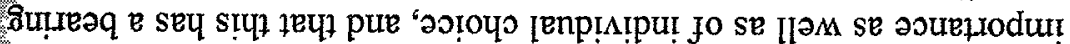

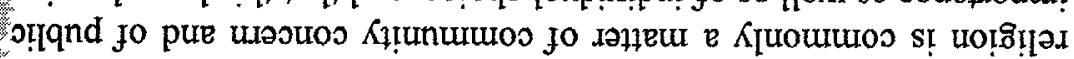

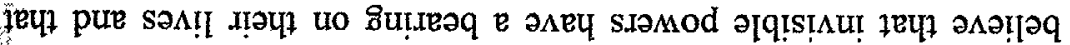

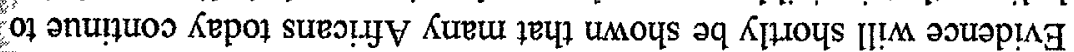

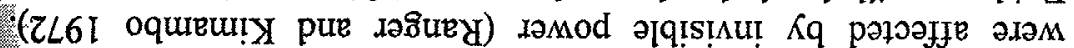

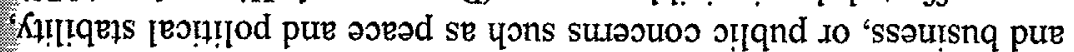

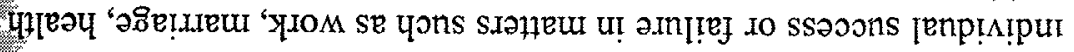

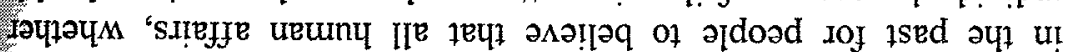

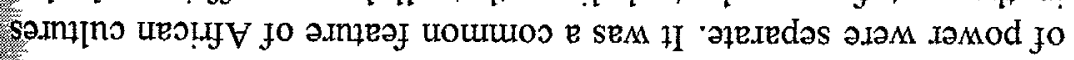




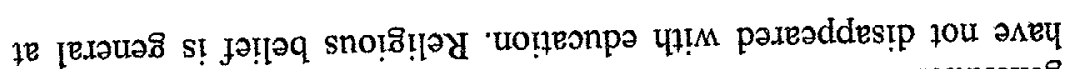

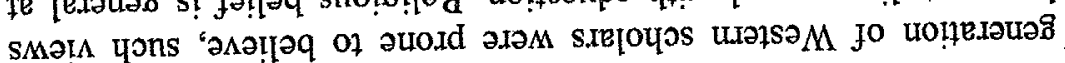

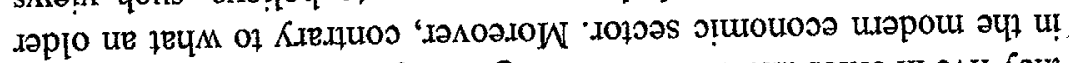

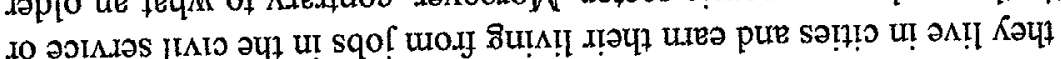

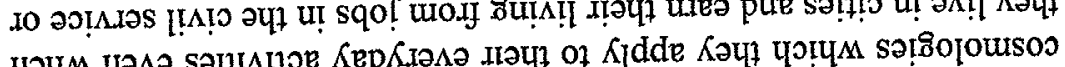

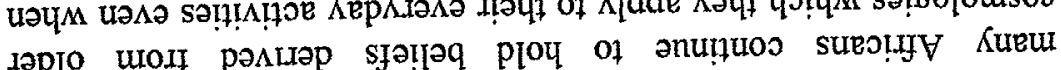

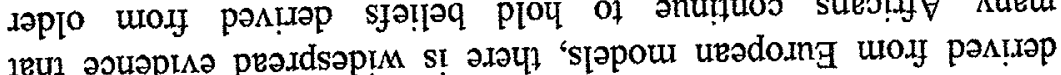

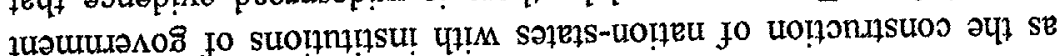

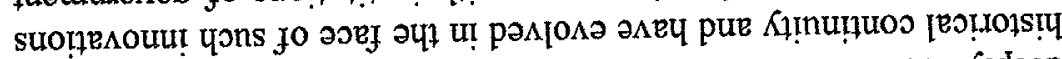

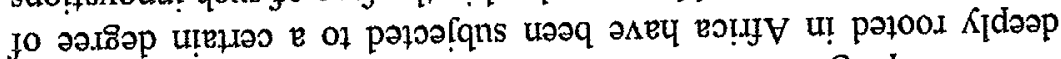

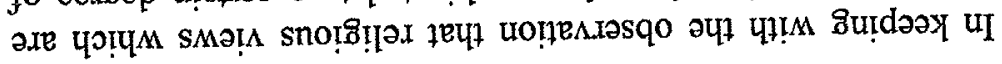

$\varsigma^{\circ}(\varsigma 961$

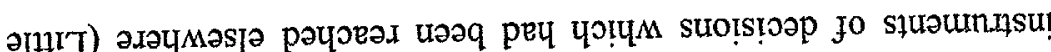

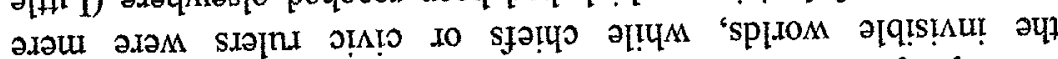

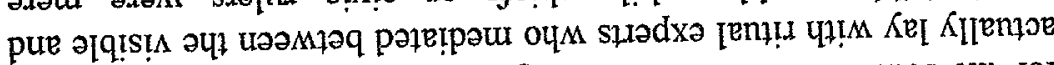

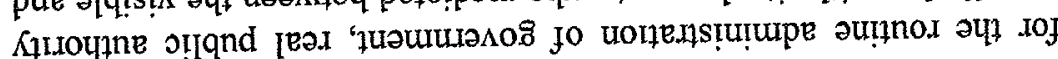

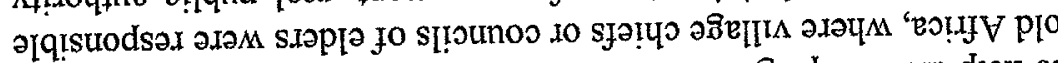

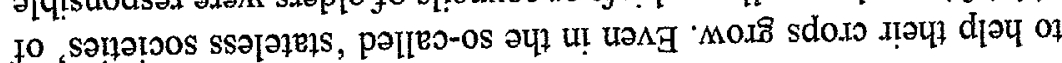

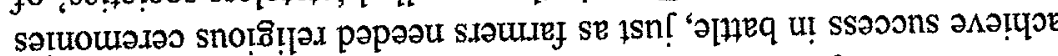

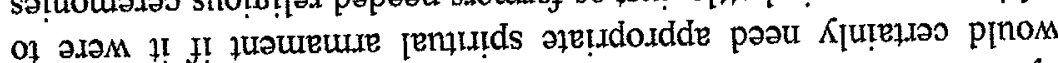

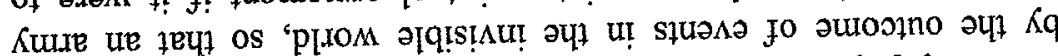

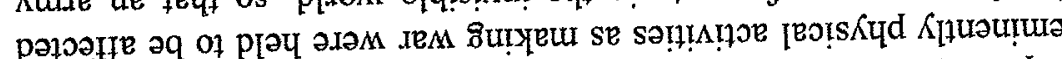

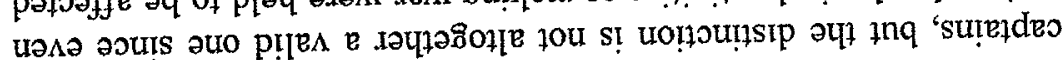

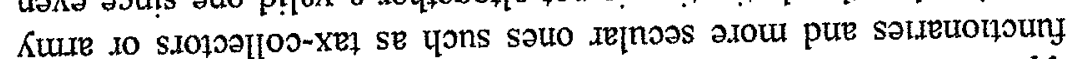

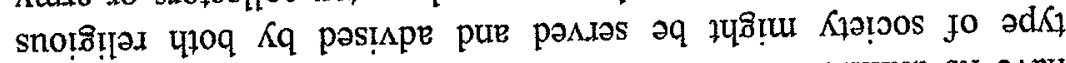

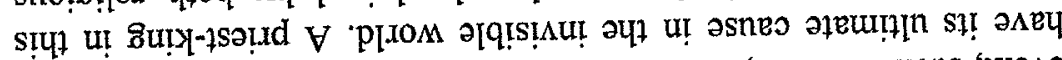

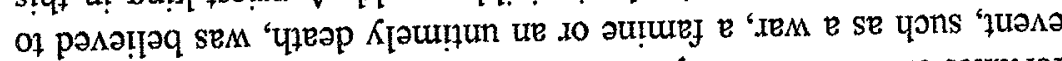

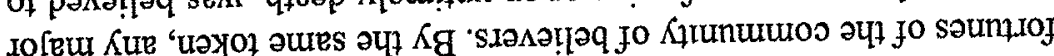

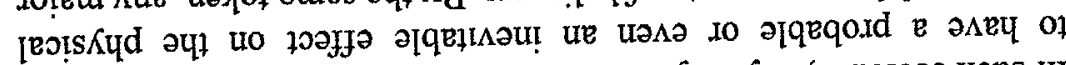

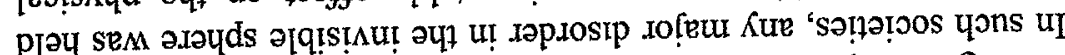

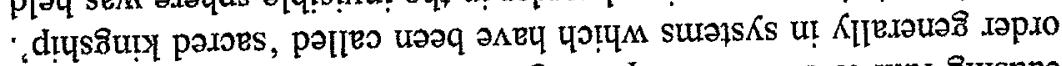

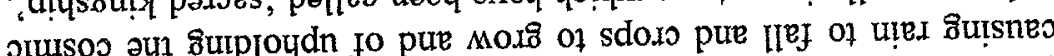

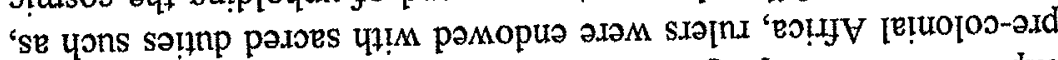

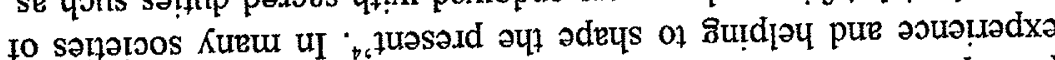
ised wouf 8ut

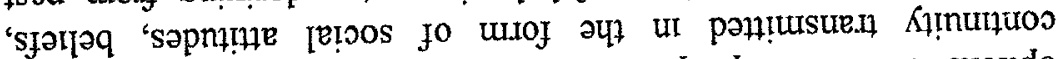

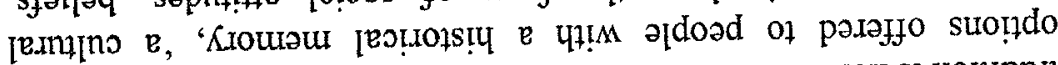

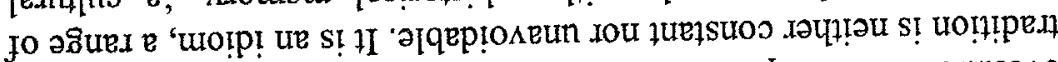

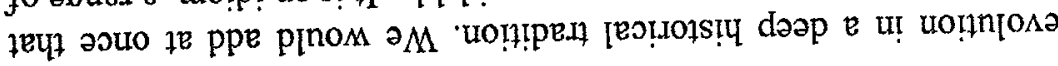

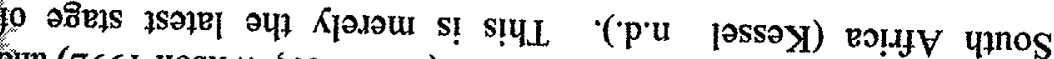

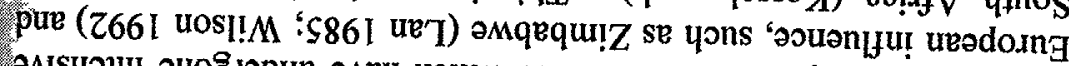

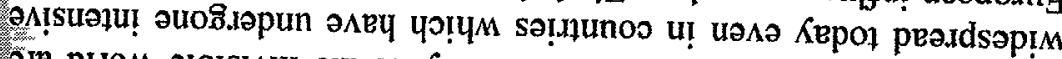

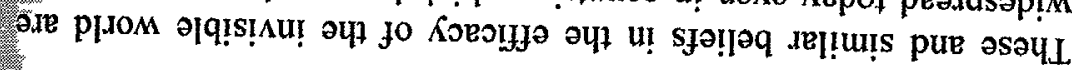
suofsesur

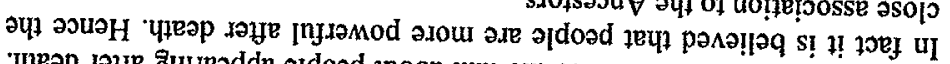

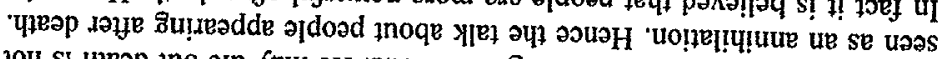

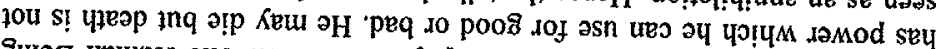

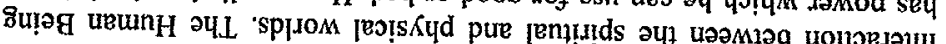

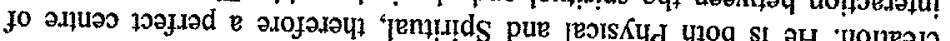

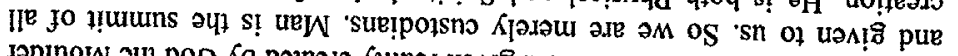

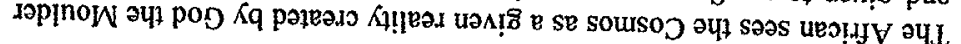

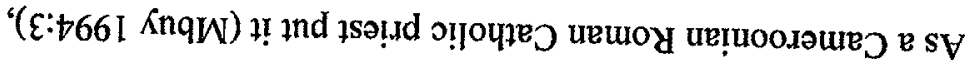

'วouef.lodur! ọuso? jo әxe pue ' мо.

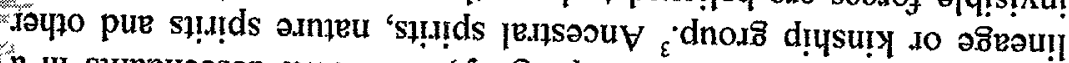

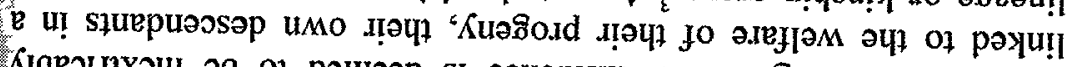

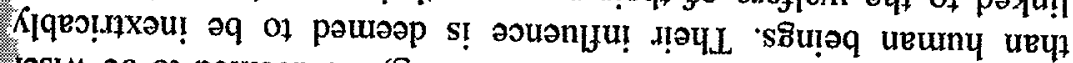

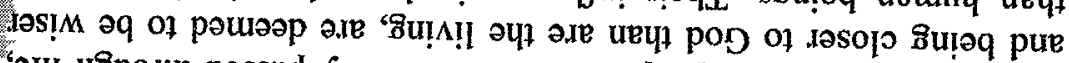

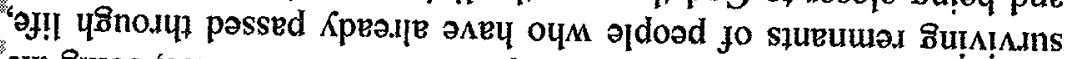

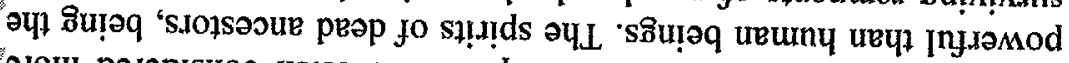

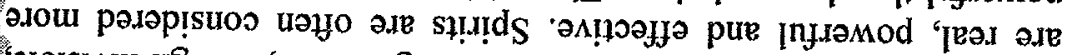

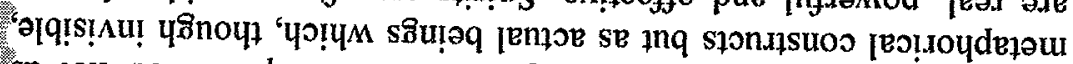

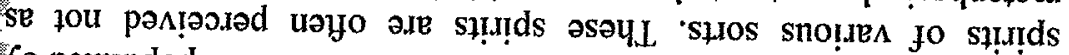

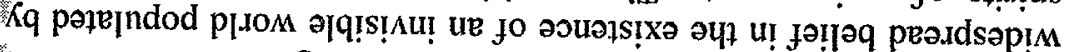

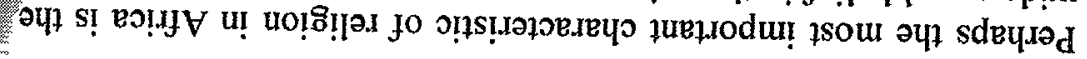

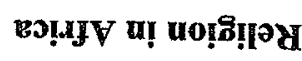

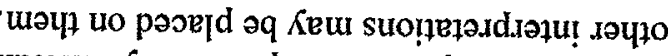

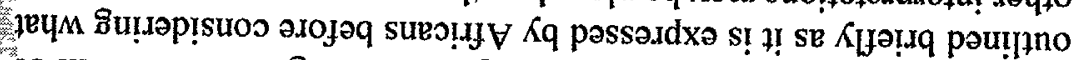

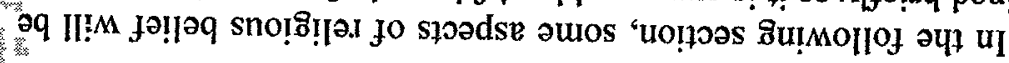

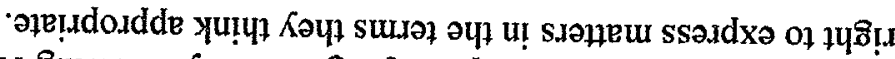

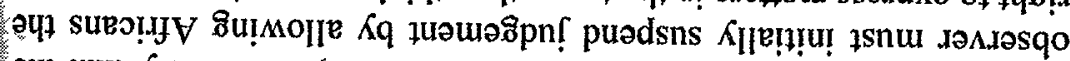

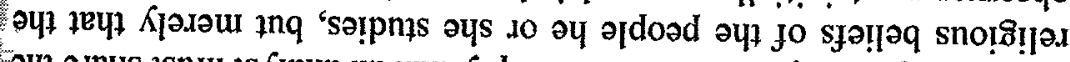

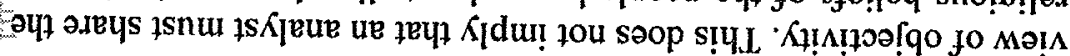
py!?

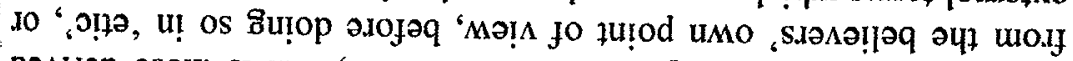

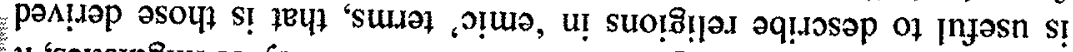

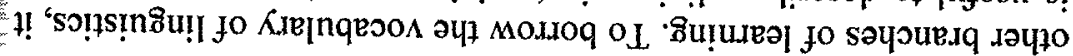




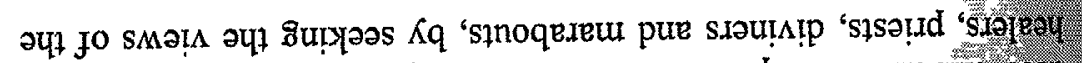

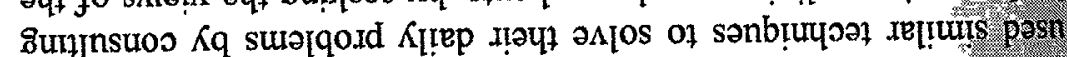

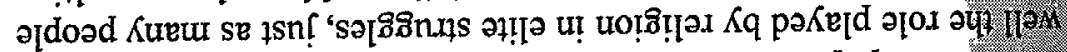

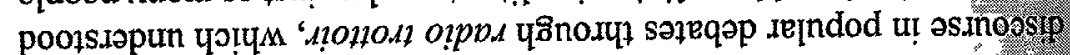

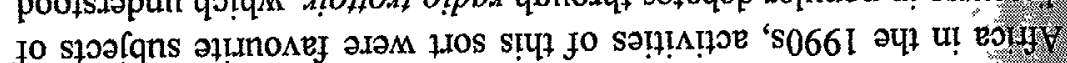

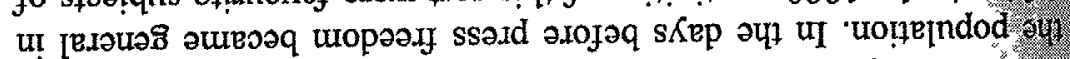

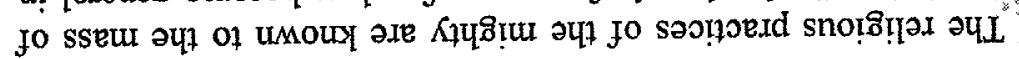

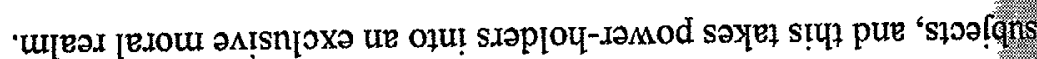

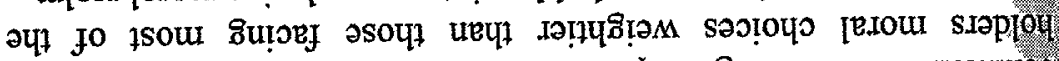

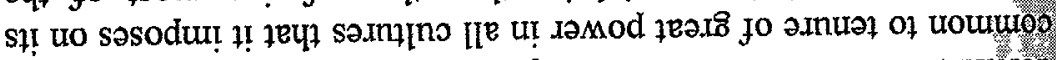

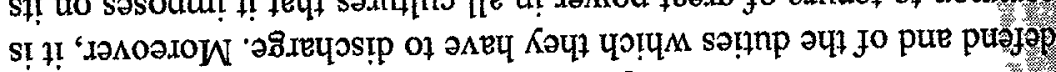

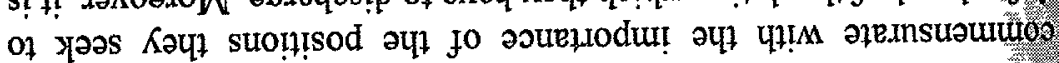

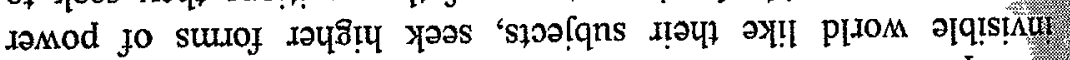

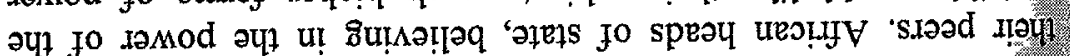

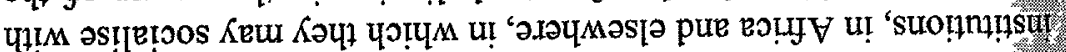

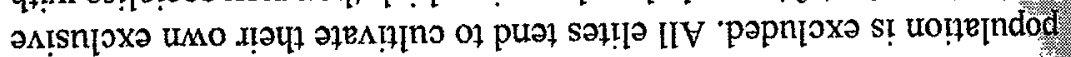

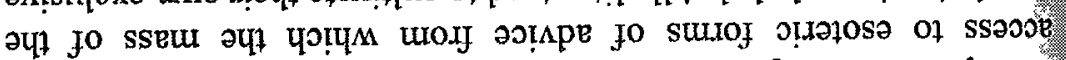

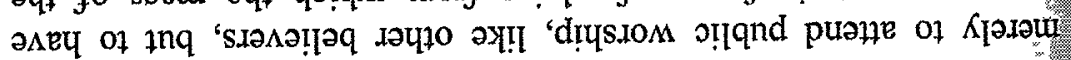

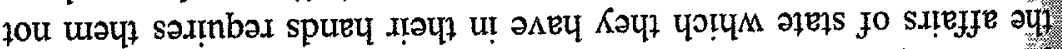

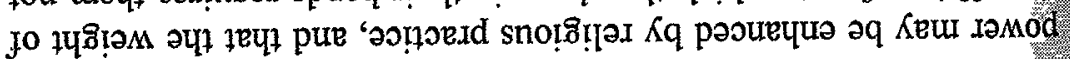

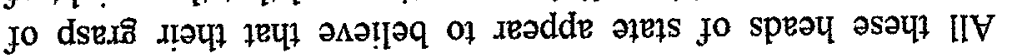

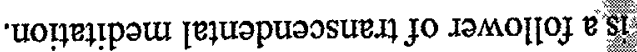

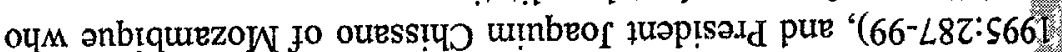

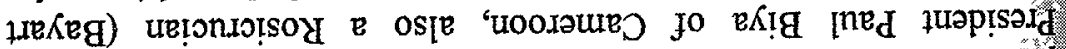

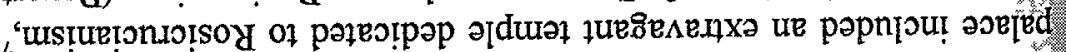

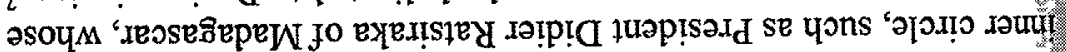

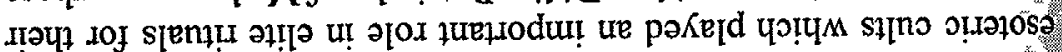

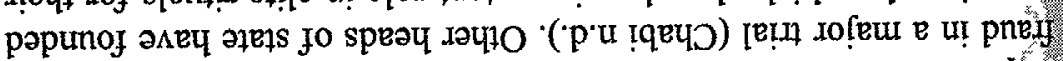

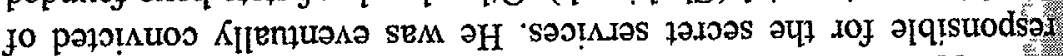

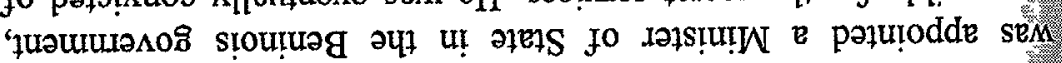

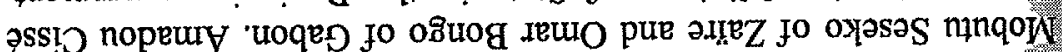

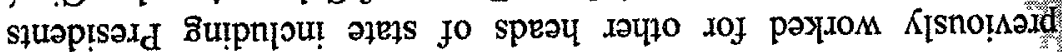

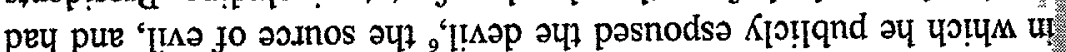

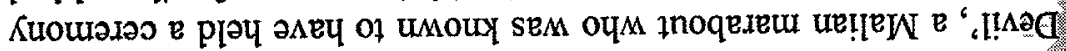

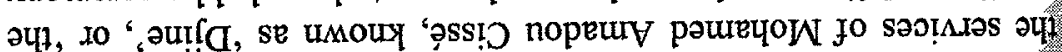

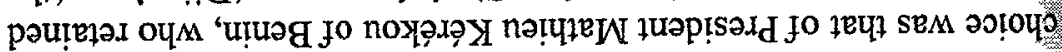

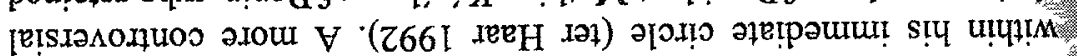

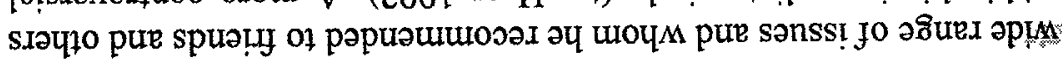

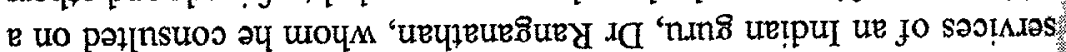

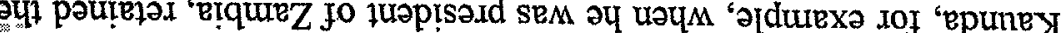

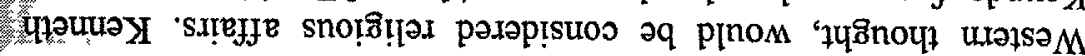

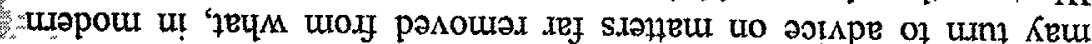

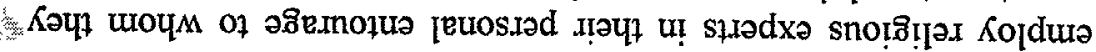

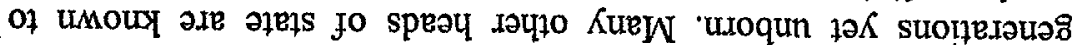

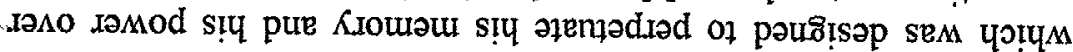

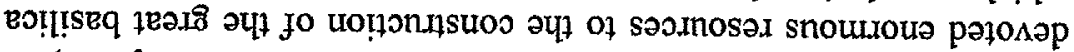

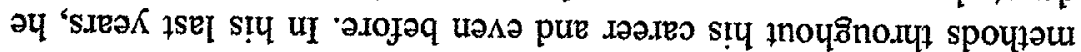

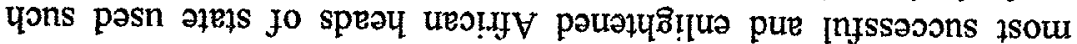

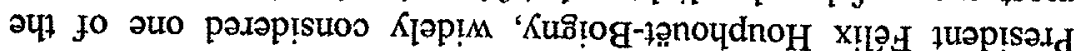

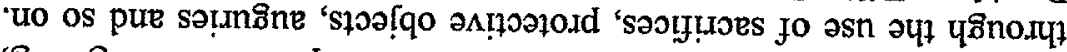

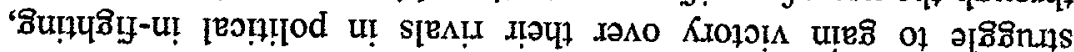

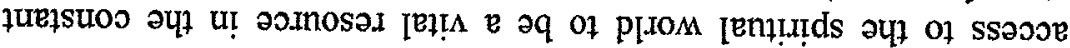

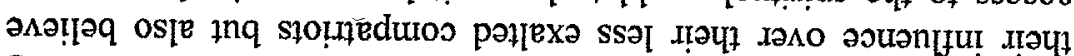

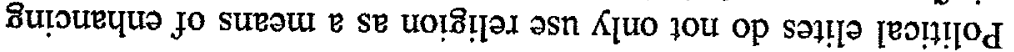

(\$86I นеT) גем әй uo uotpendod әчł fo uolut

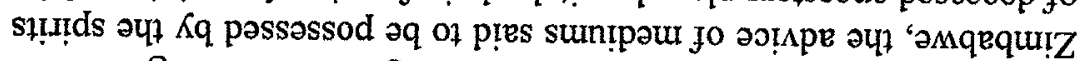

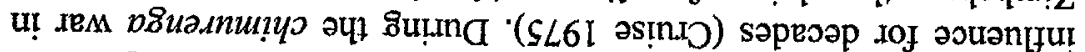

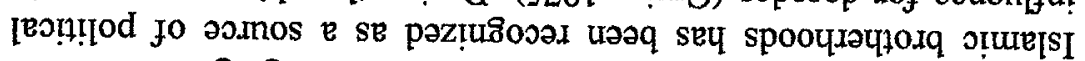

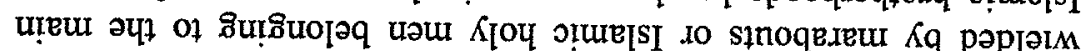

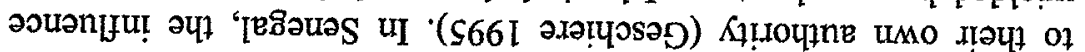

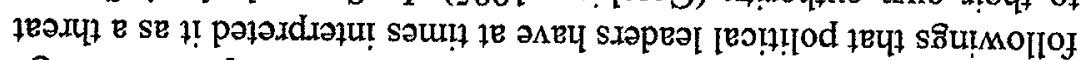

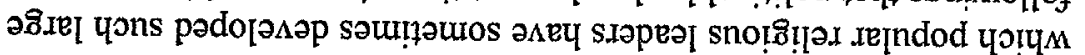

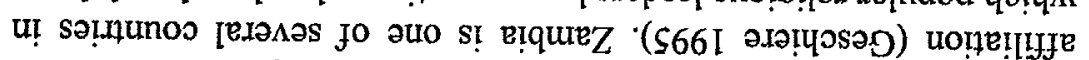

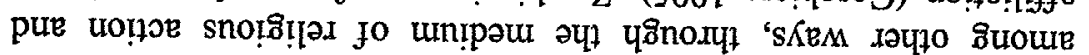

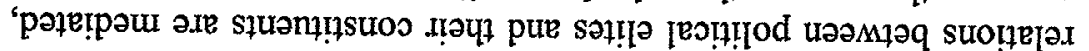
'นooxəure

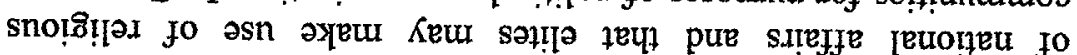

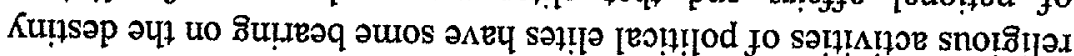

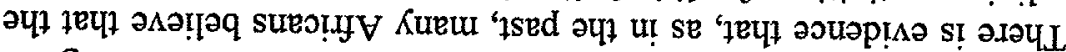

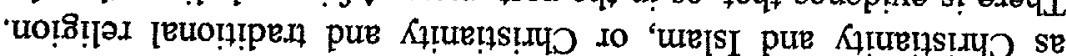

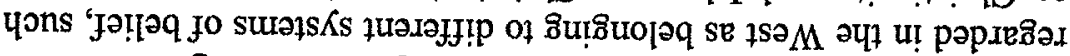

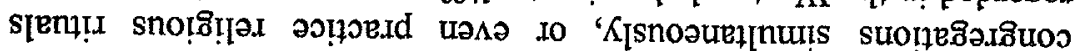

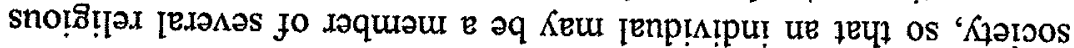

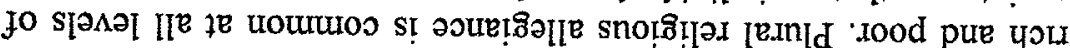

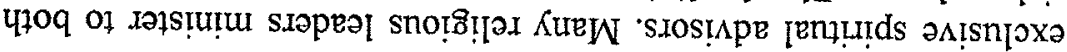

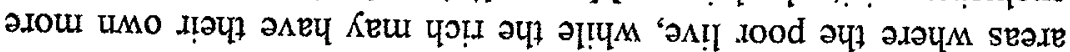

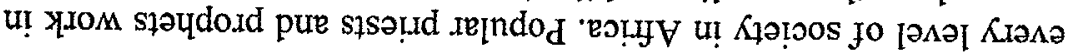


Jof uoneue uo วnnbอe of Ұ[

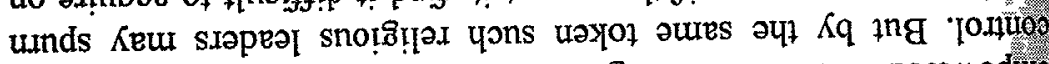

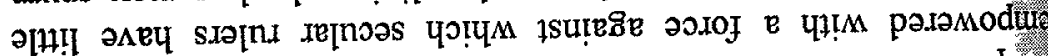

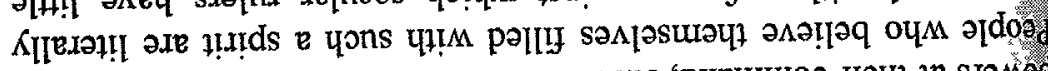

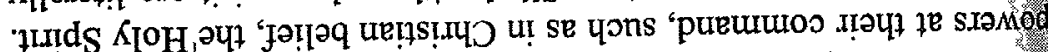

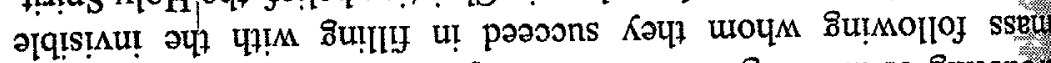

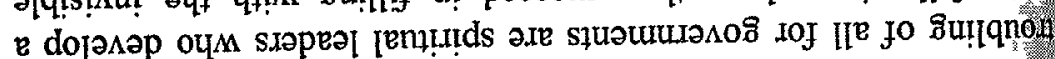

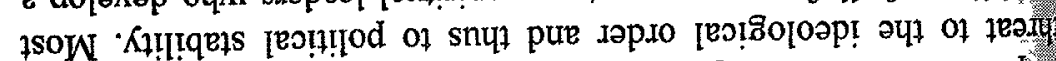

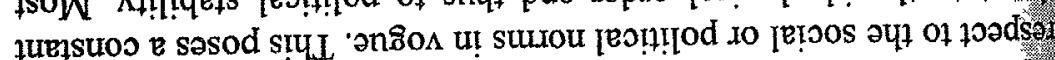

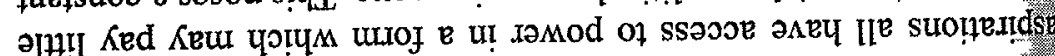

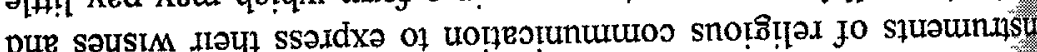

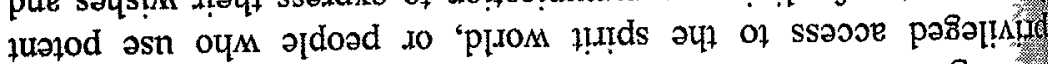

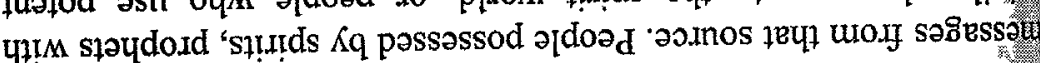

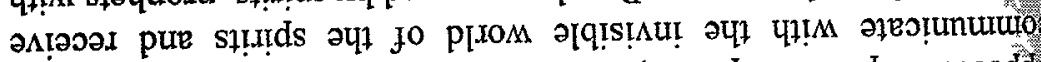

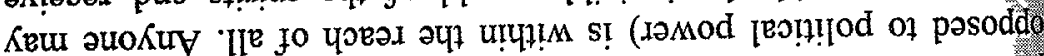

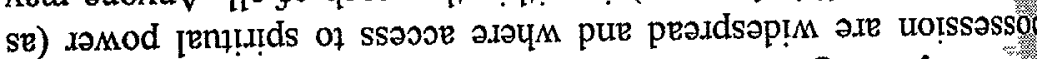

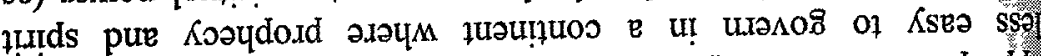

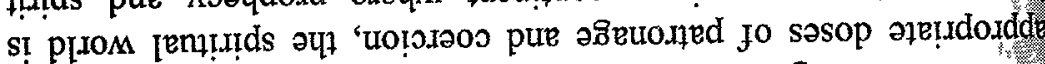

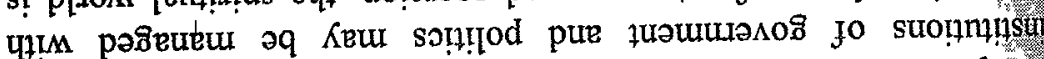

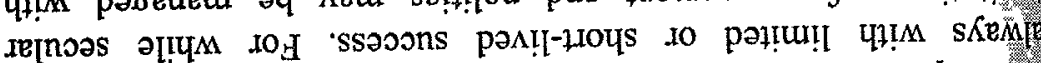
Inq 'dtussiuny paises jo suałs

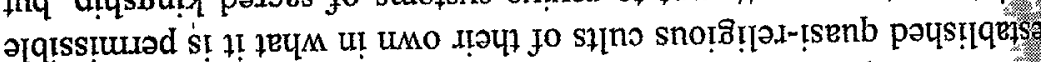

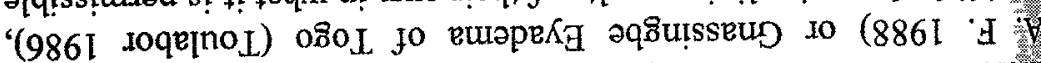

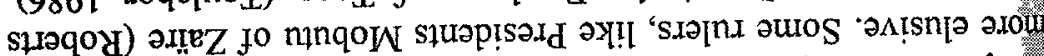

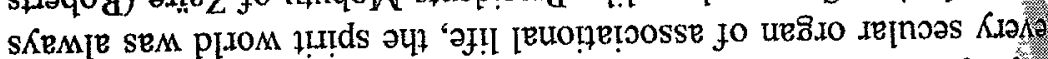

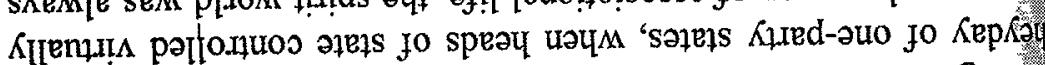

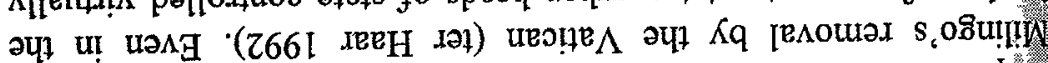

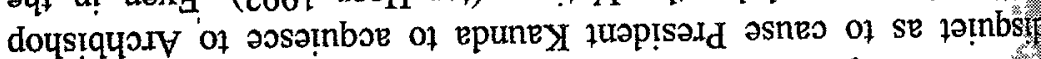

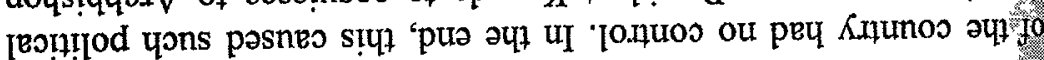

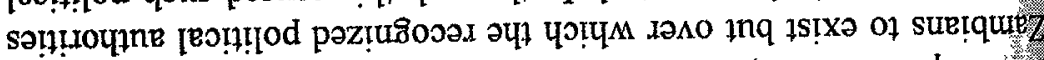

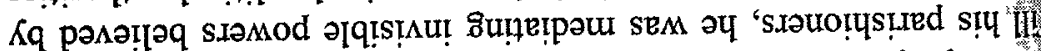

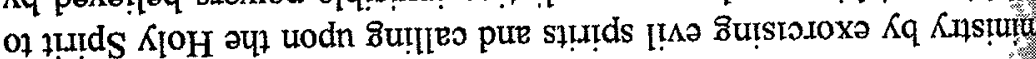

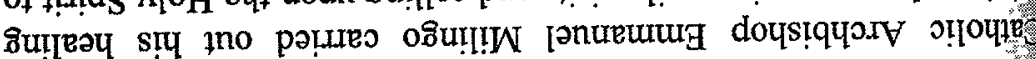

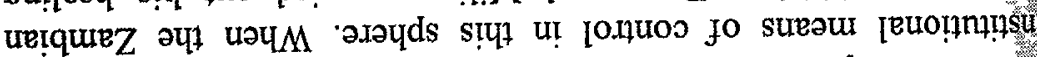

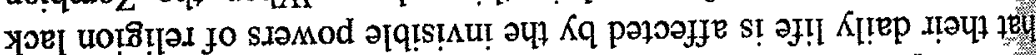

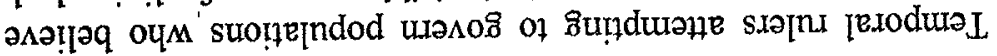

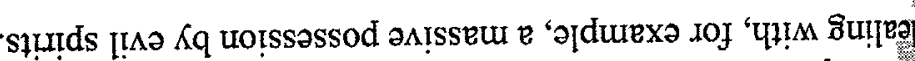

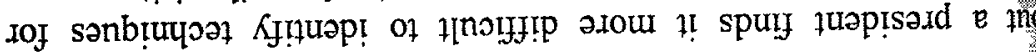

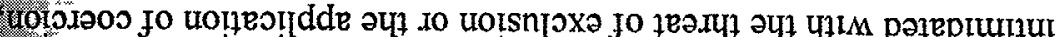

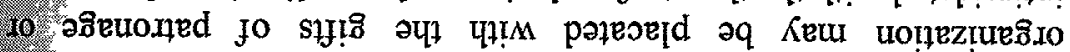

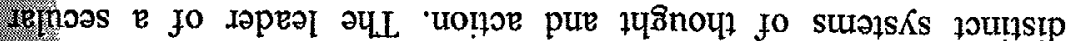

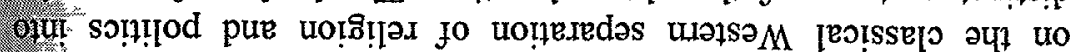

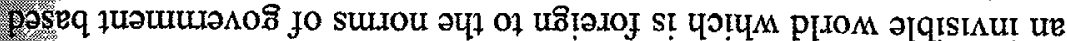

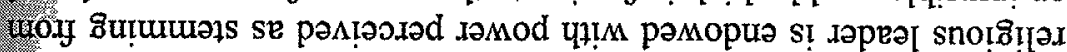

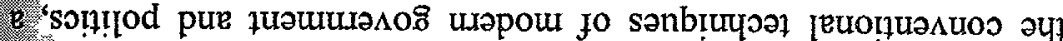

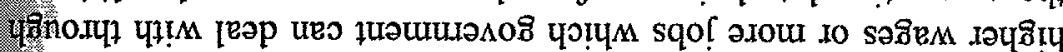

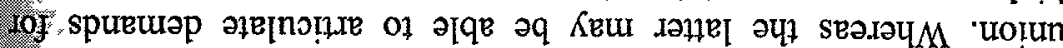

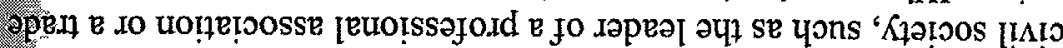
jo

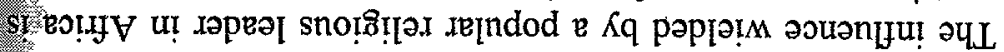
(2)

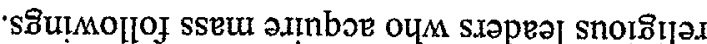

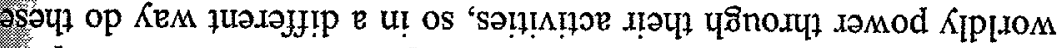

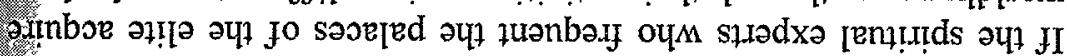

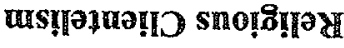

'xamod je.Inłeuradns

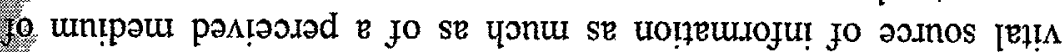

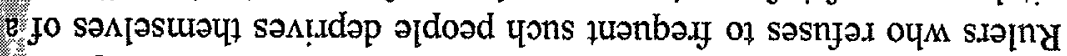

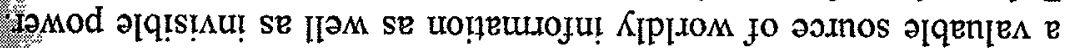

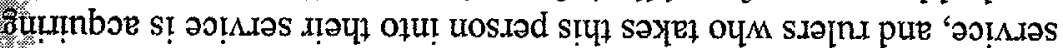

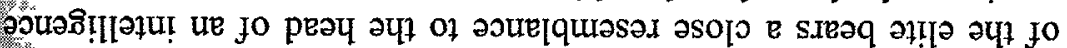

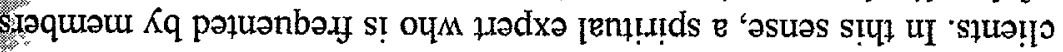

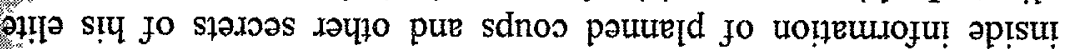

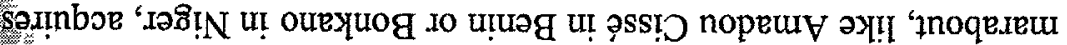

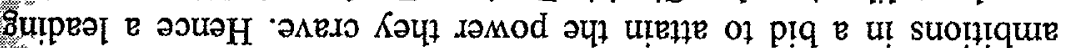

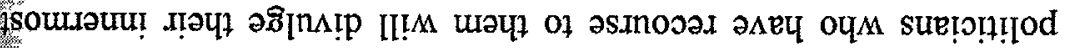

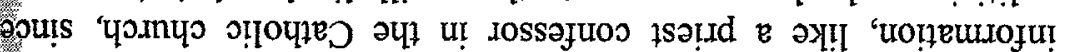

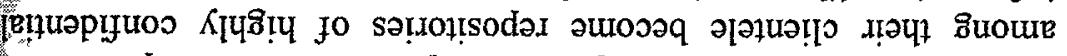

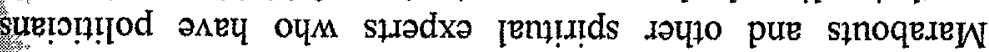

(L-ISI:S66I IURURtT)

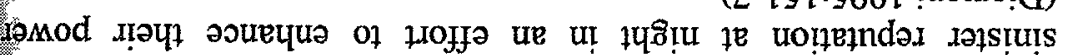

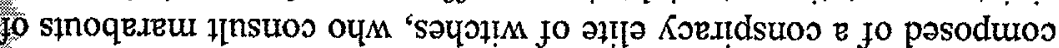

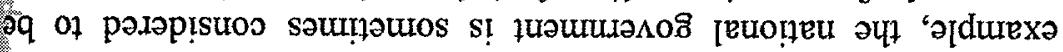

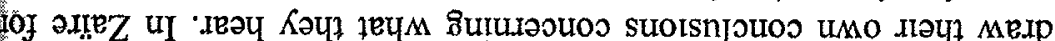

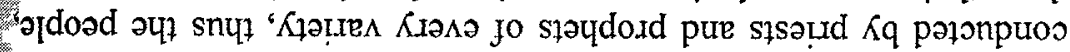

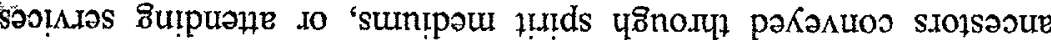




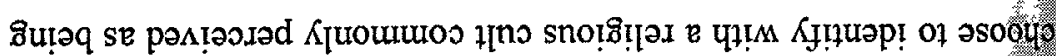

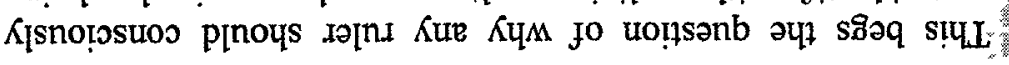

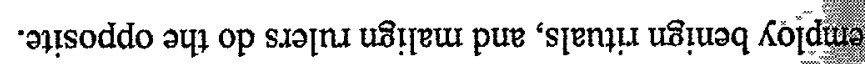

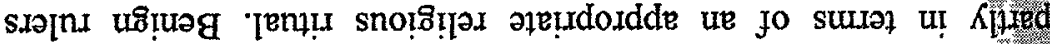

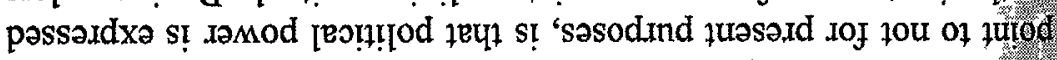

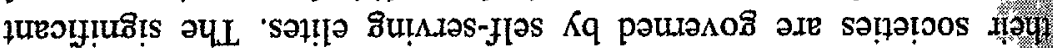

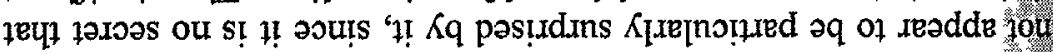

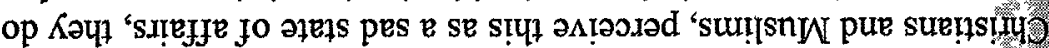

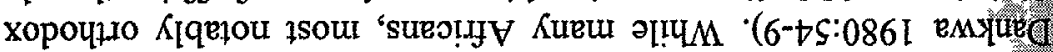

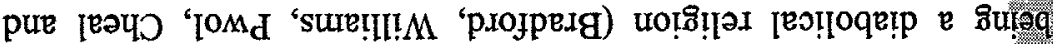

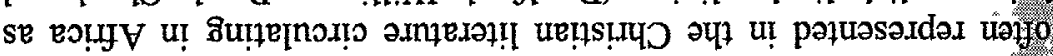

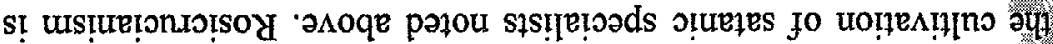

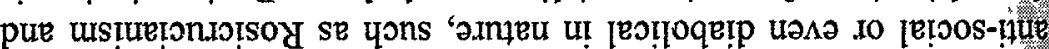

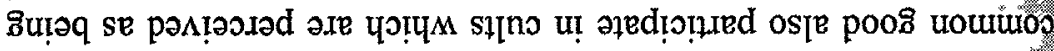

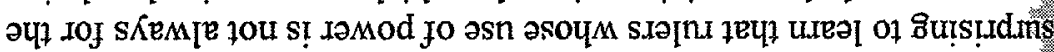

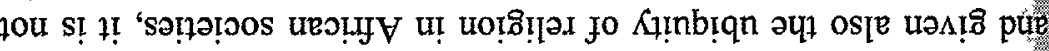

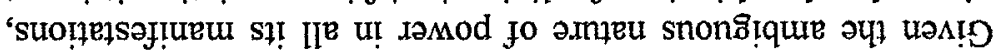

'suont?u丶tu

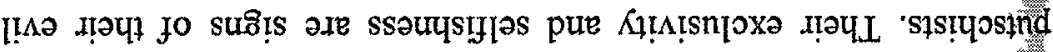

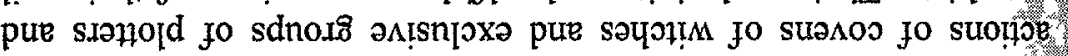

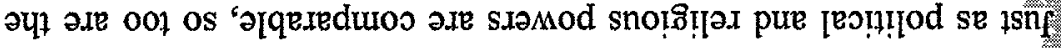

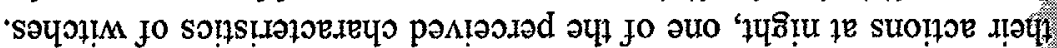

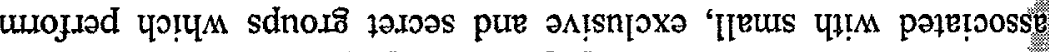

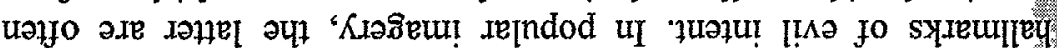

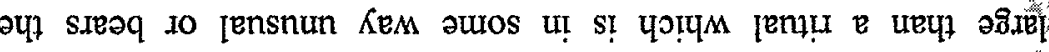

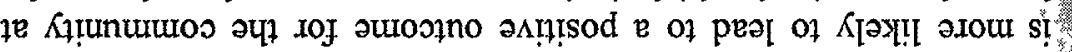

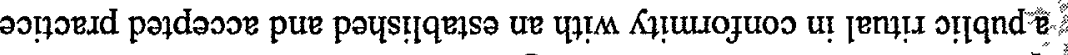

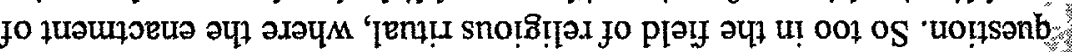

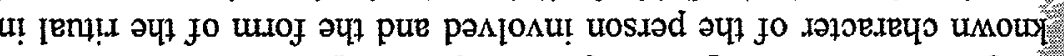

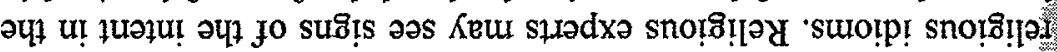

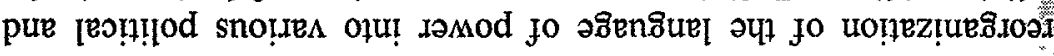

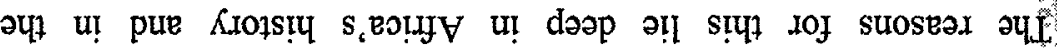

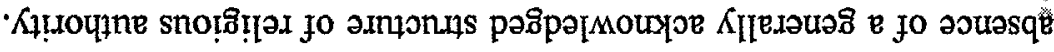

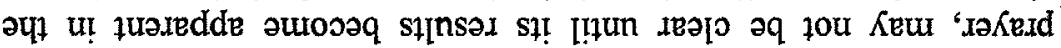

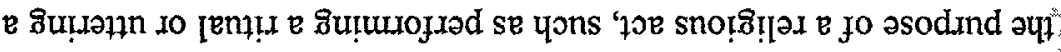

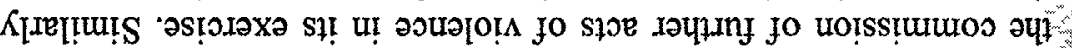

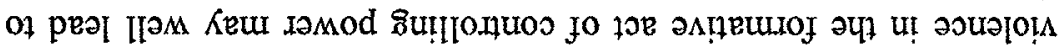

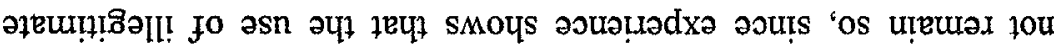

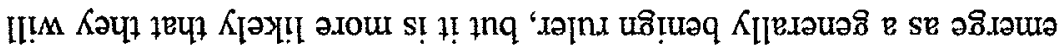

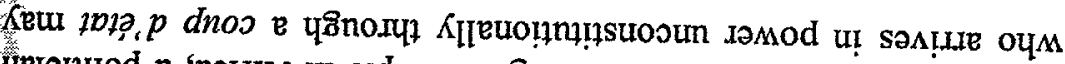

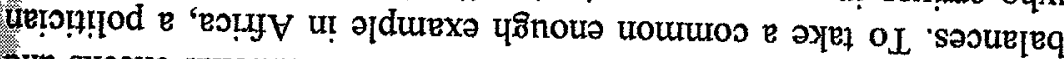

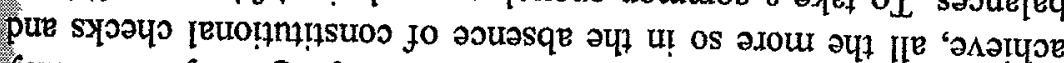

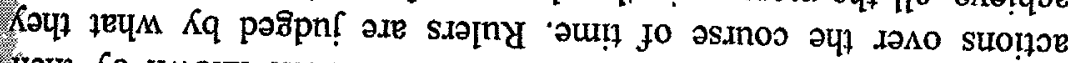

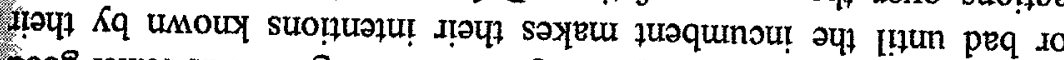

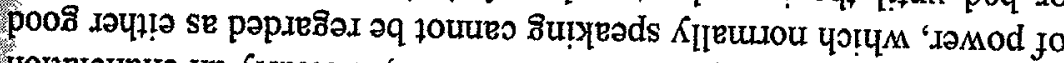

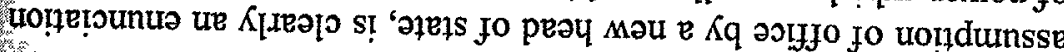

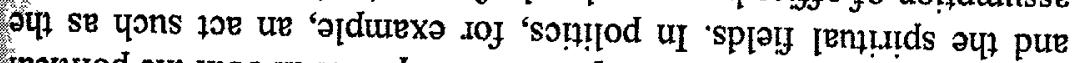

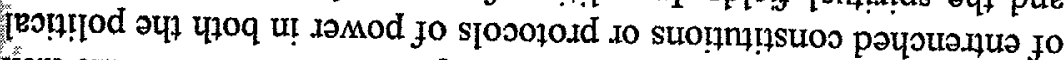

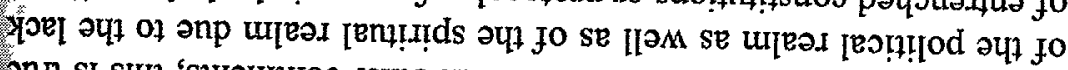

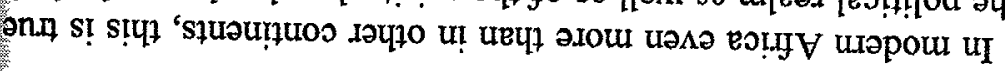

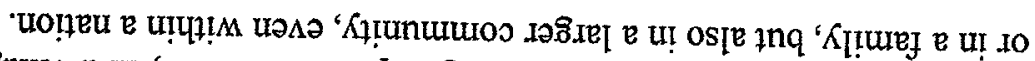

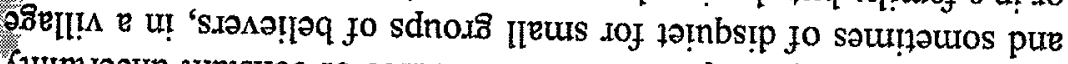

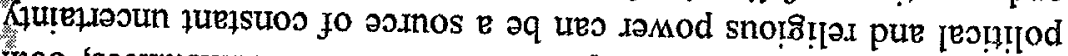

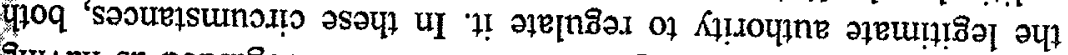

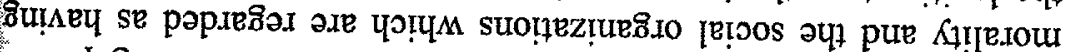
o!

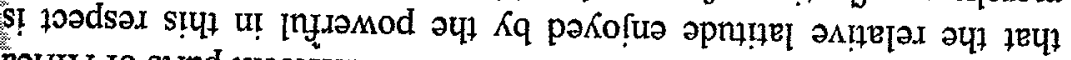
हouf

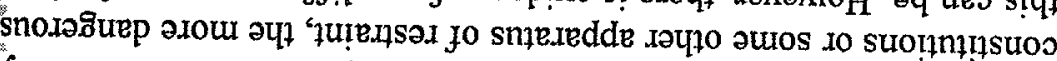

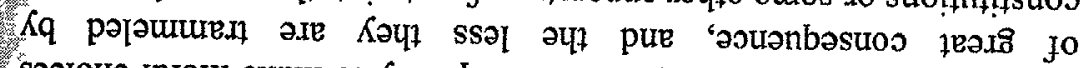

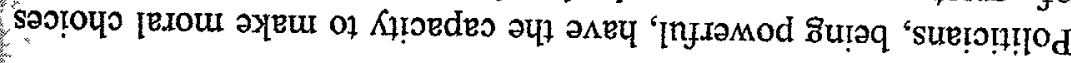

s.opvat pomplod

$\therefore$ II

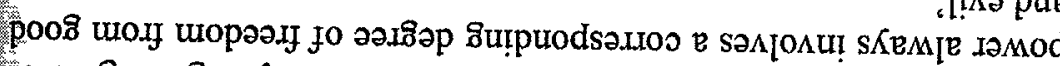

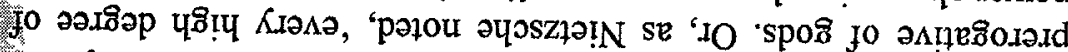

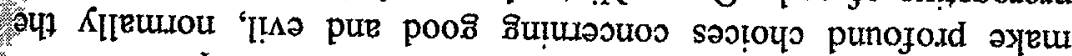

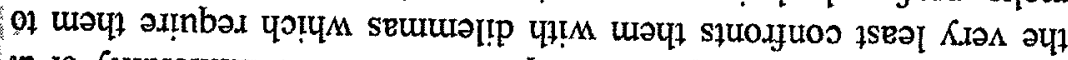

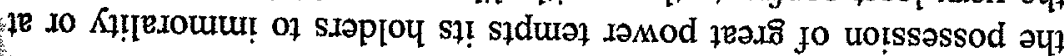

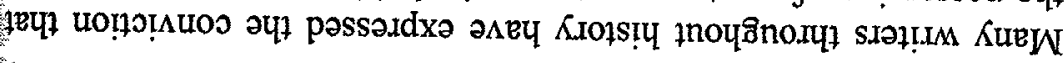

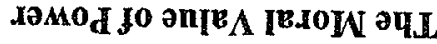

(ZL- $29 \varepsilon \cdot \mathrm{dd}$

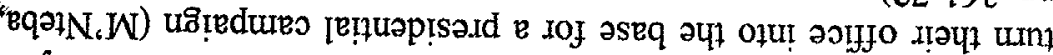
of Kiəx!fun anq sue!ont

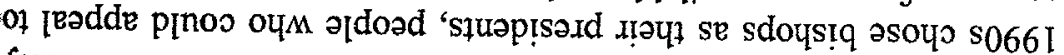

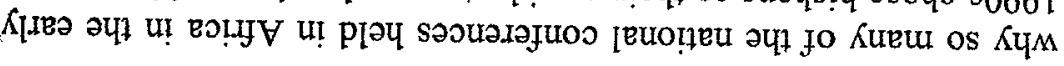


fou әเฺฯ $M$ '

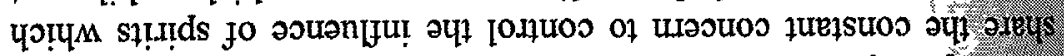

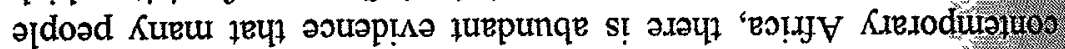

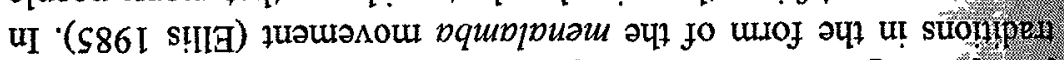

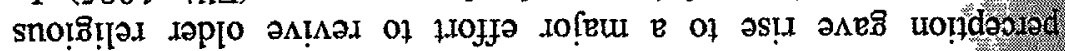

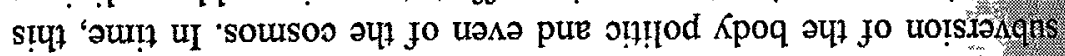

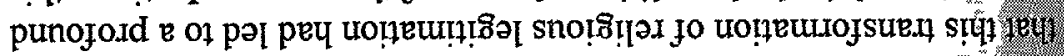

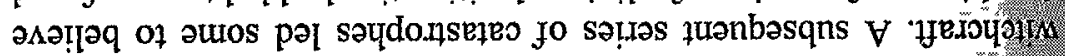

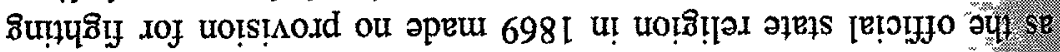

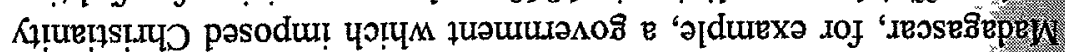

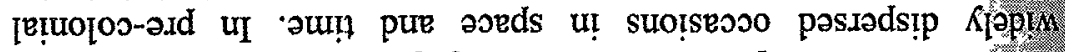

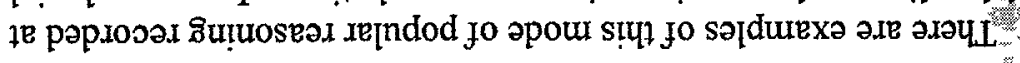

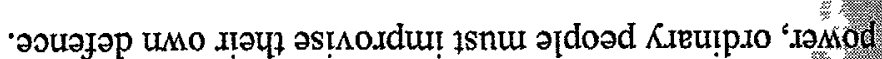

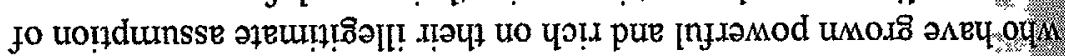

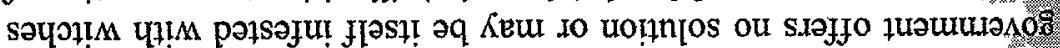

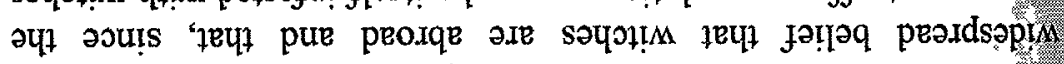

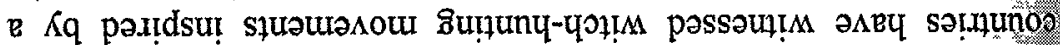

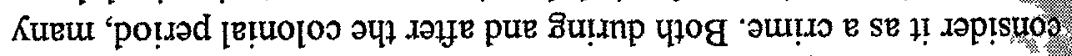

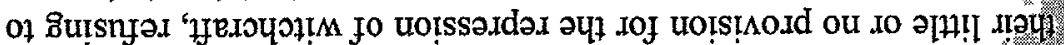

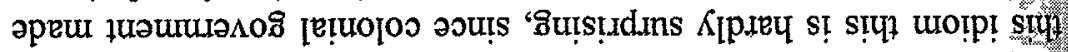

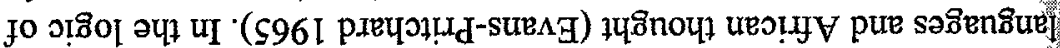

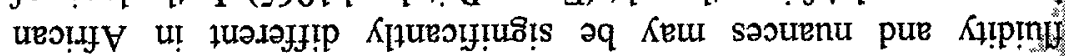

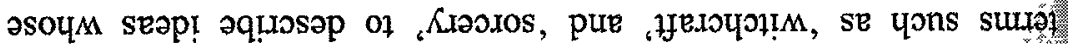

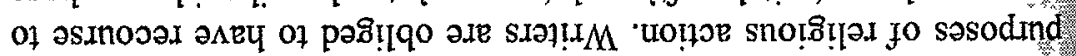

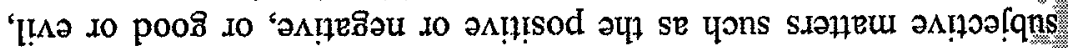

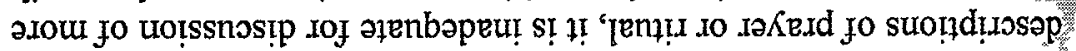

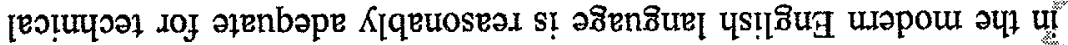
uo! 8 [1ว

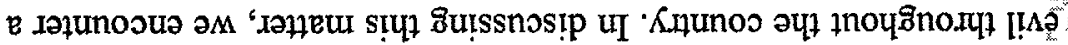

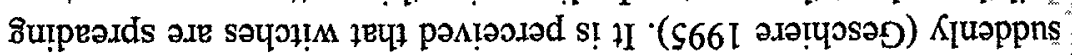

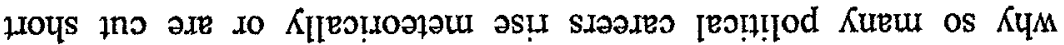

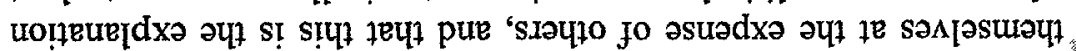

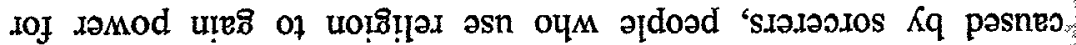

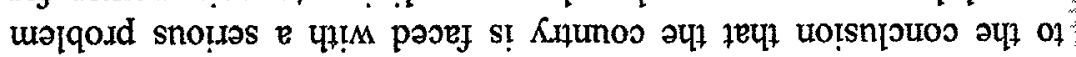

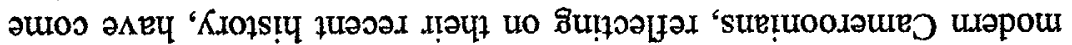

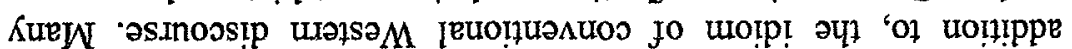

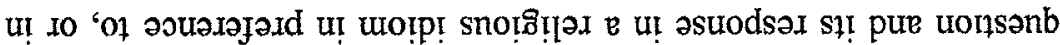

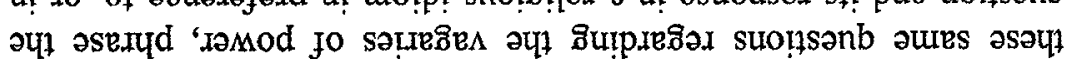

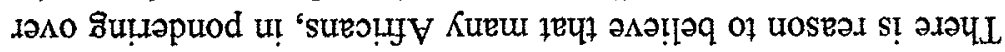

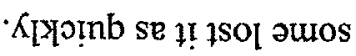
son!!

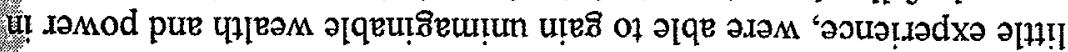

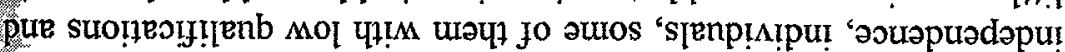

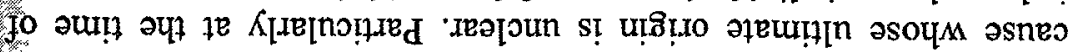

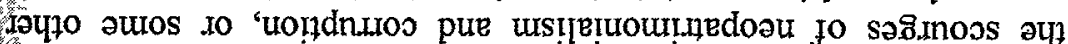

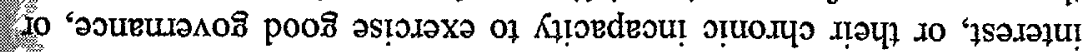

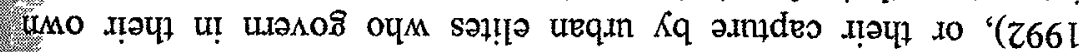

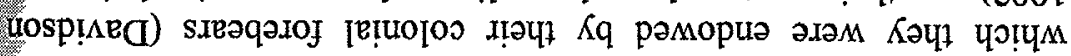

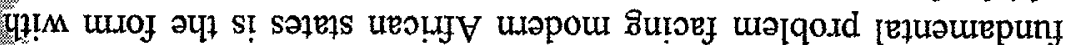

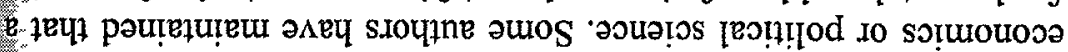

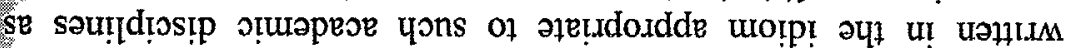

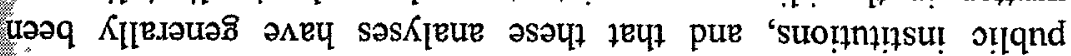

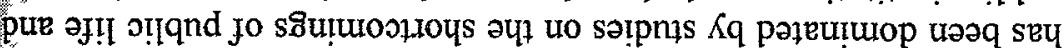

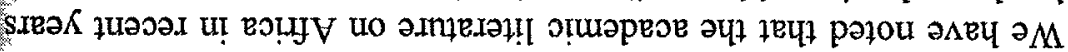

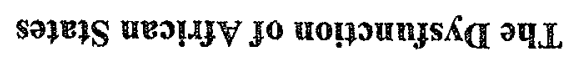

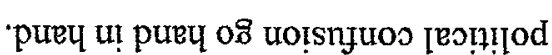

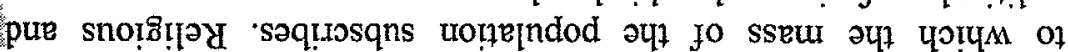

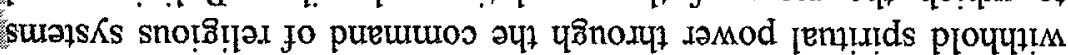

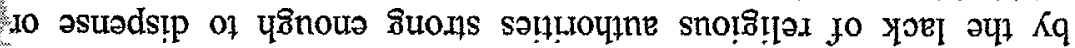
paxounu s! s.ə[nı uroụ

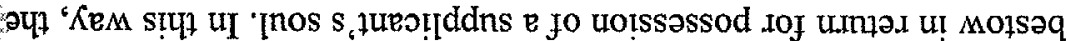

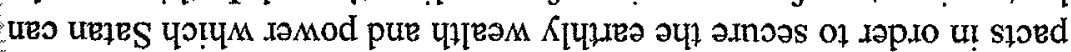

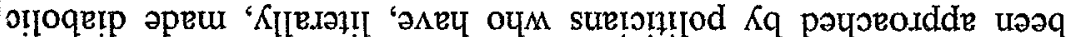

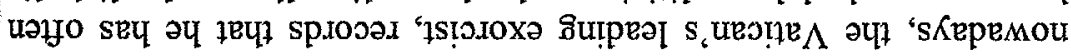

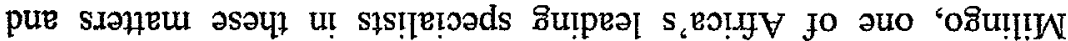

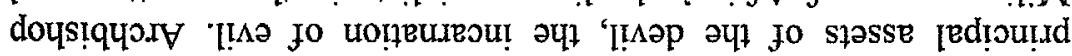

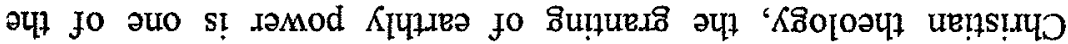

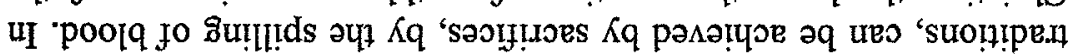

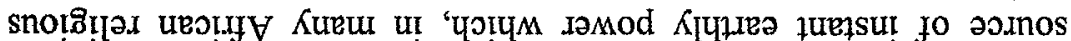

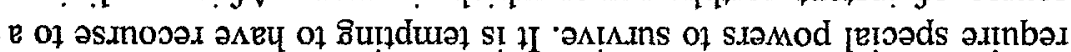

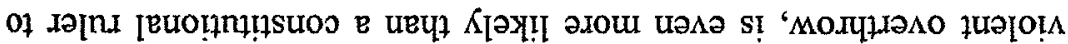

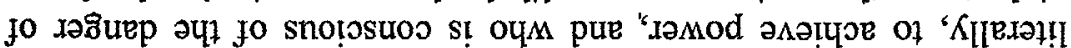

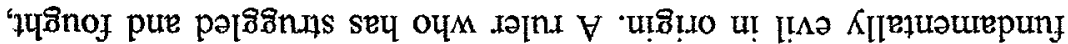

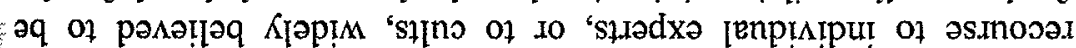

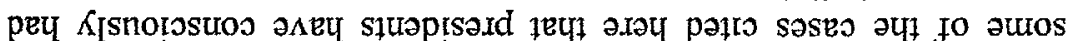

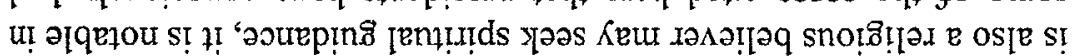

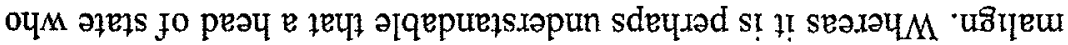

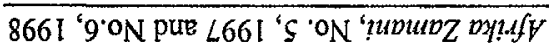




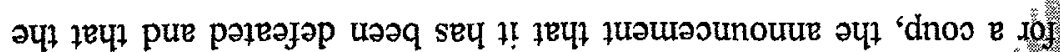

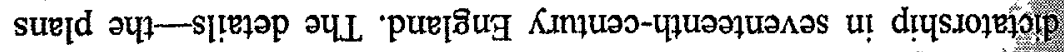

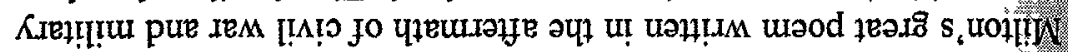

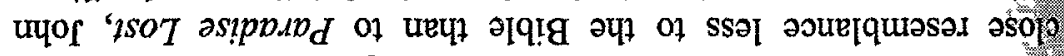

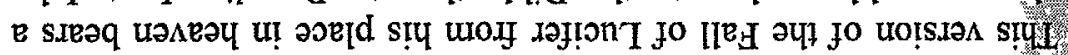

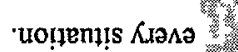

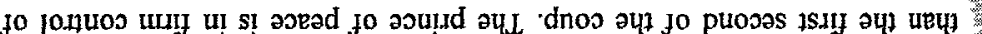

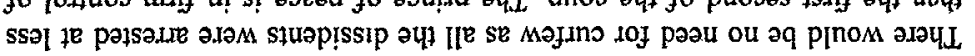

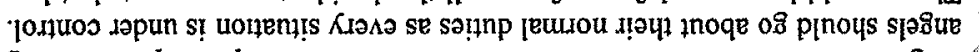

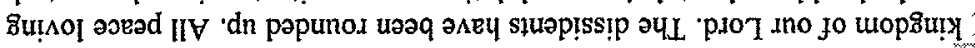

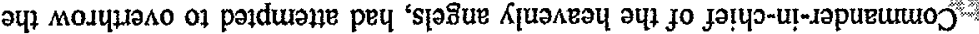

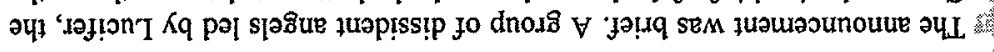

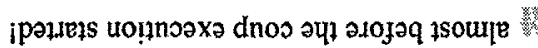

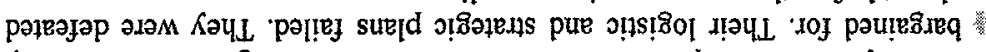

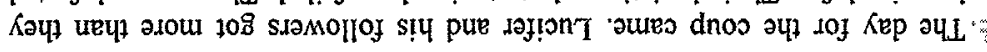

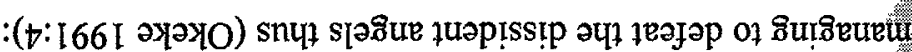

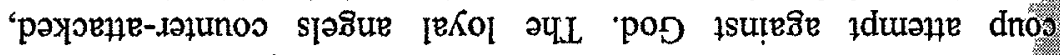

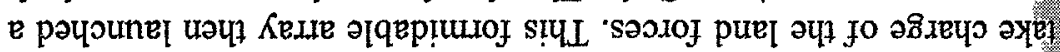

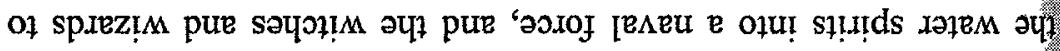

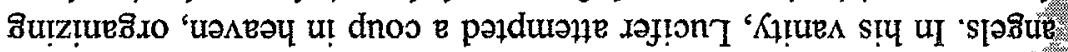

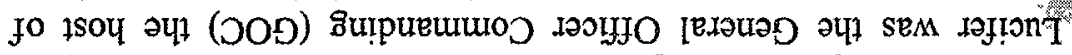

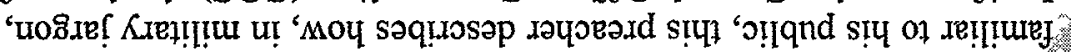

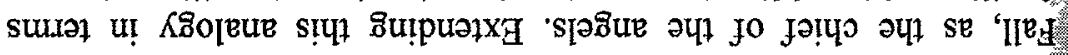

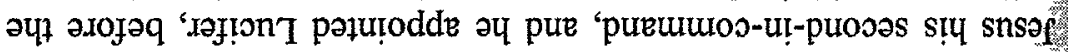

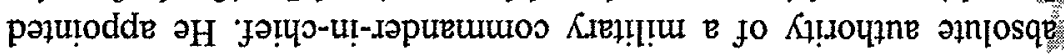

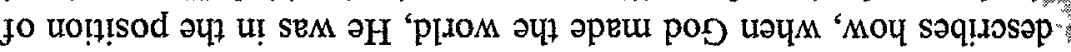
II "II

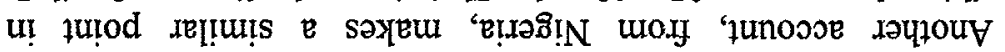

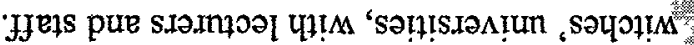

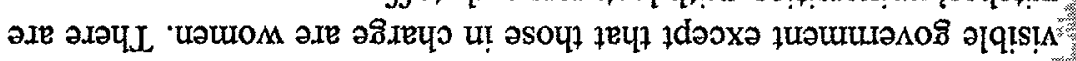
e әม!

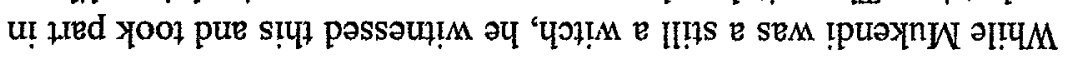

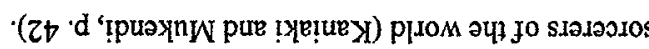
fo uo!̣ez! do s1s!!

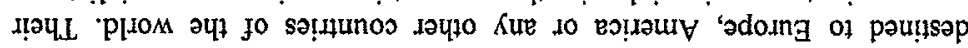

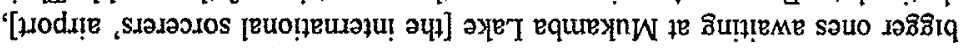

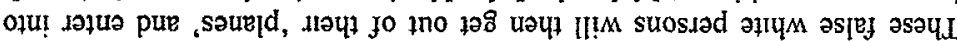

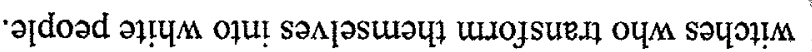
ueouy

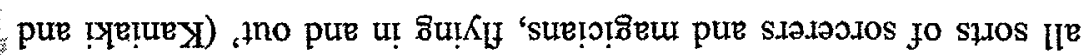

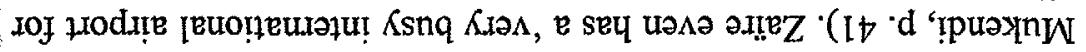

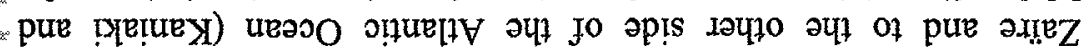

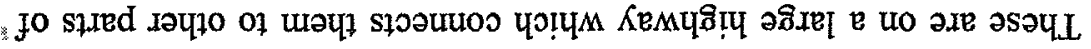

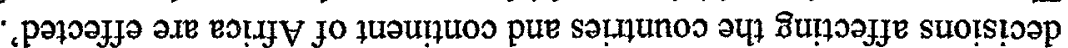

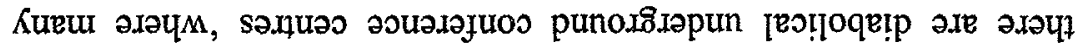

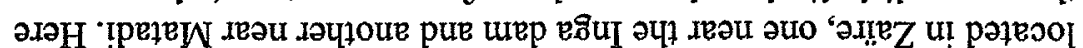

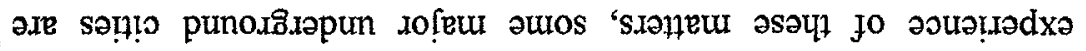

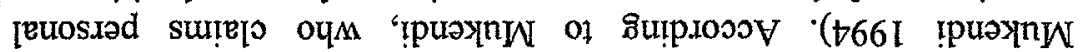

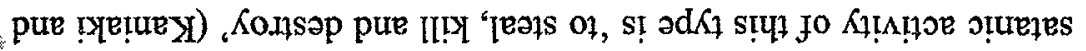

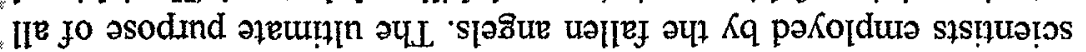

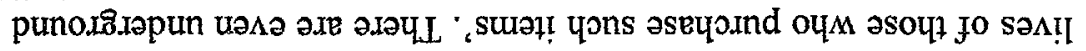

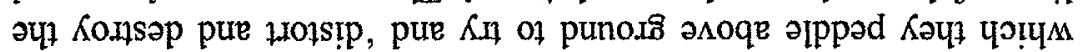

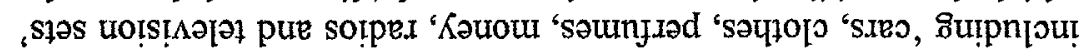

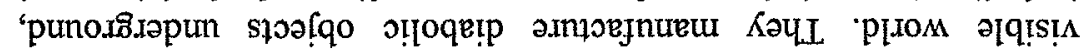

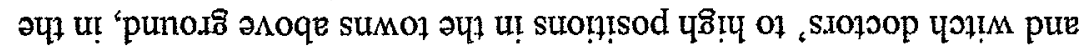

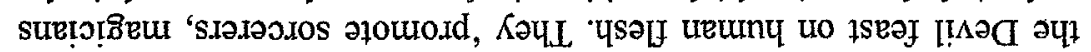

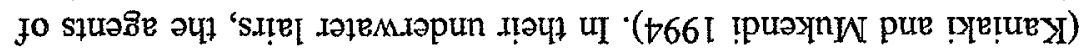

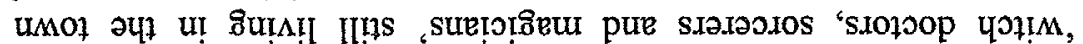

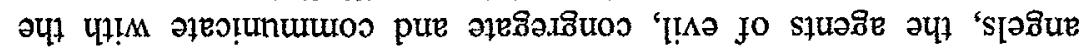

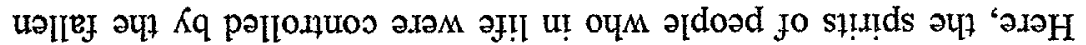

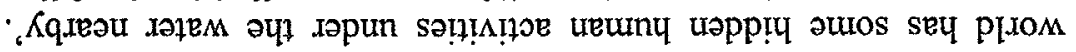

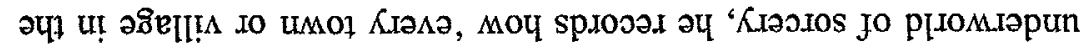

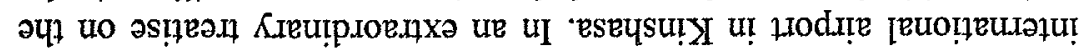
ue pure salı!sıantun sutpnjout 'sәy

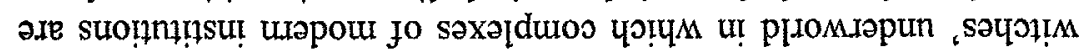

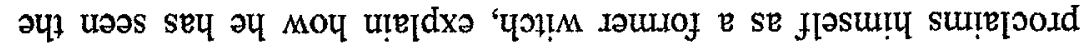

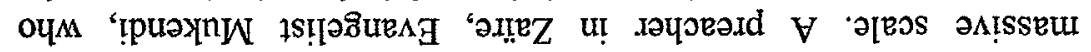

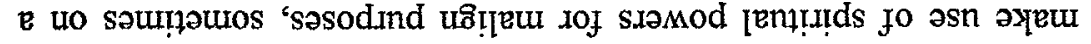

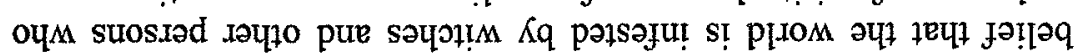

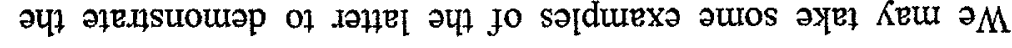

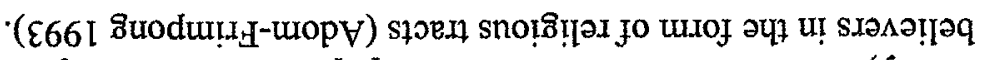

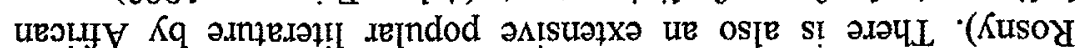

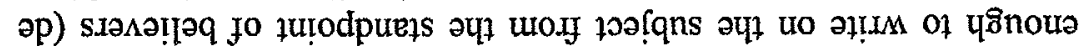

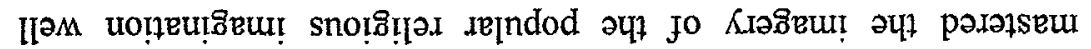

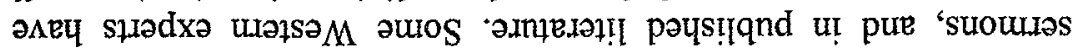

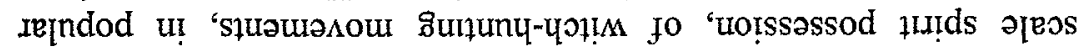

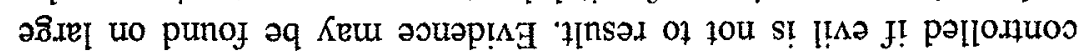

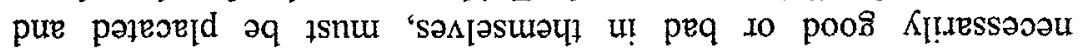




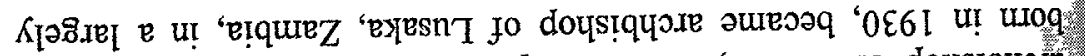

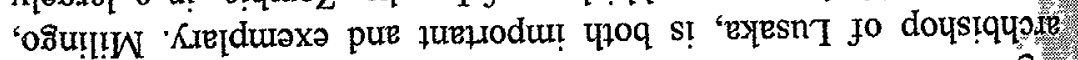

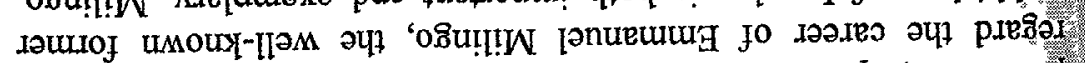

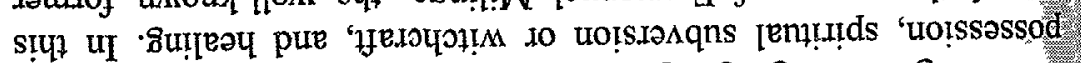

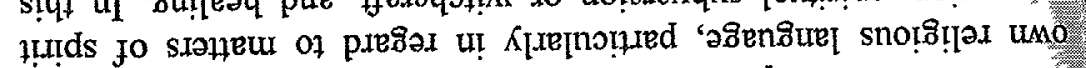

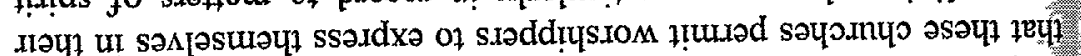

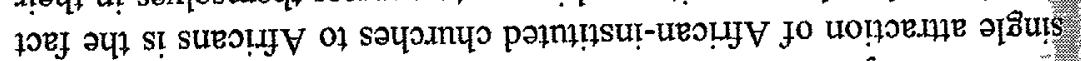

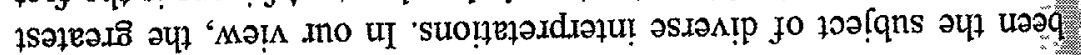

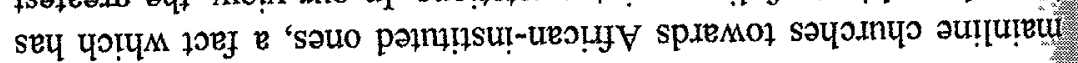

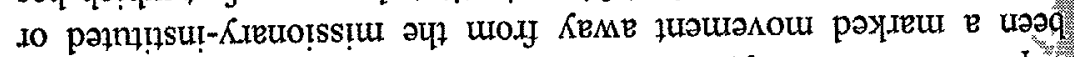

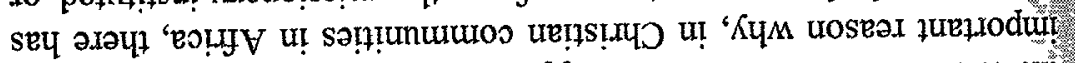

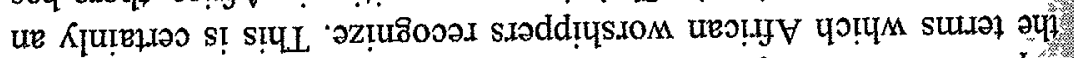

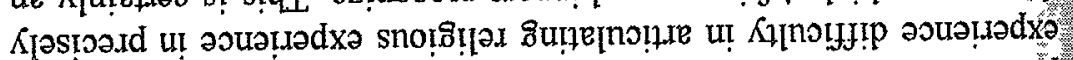

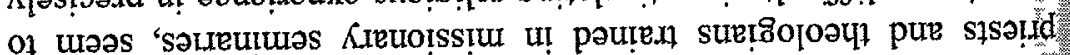
se yons 'wo!!

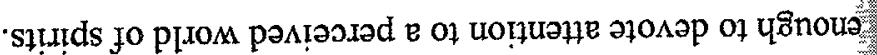

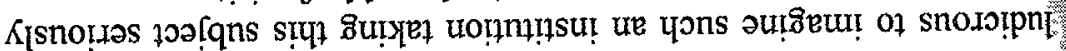

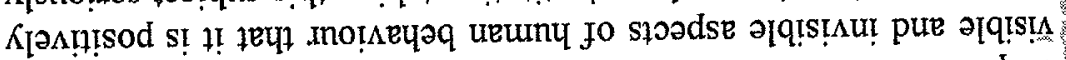

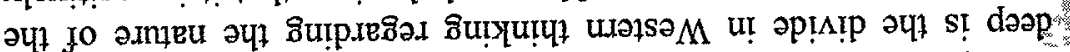
os ‘uotol!

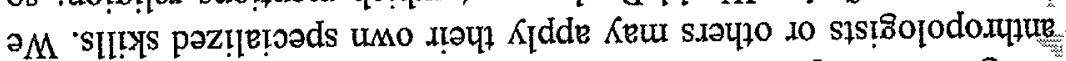

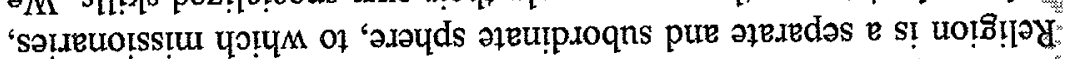

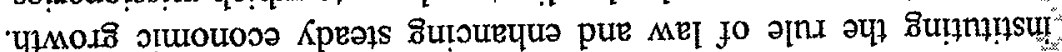

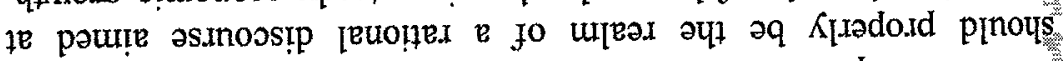

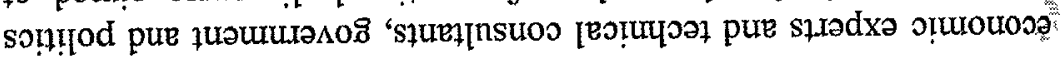
Kq eอ!ฺ

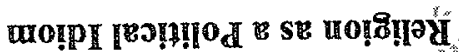

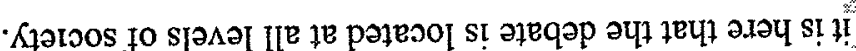

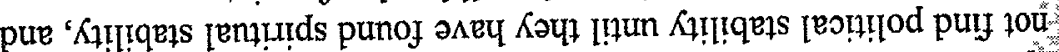

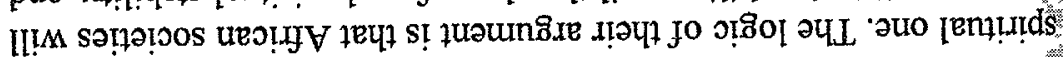

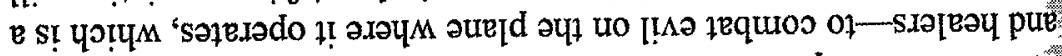

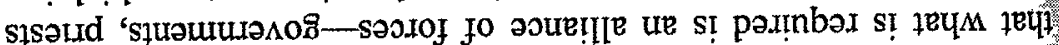

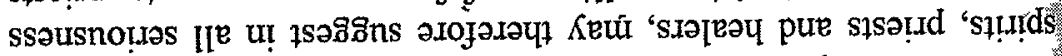

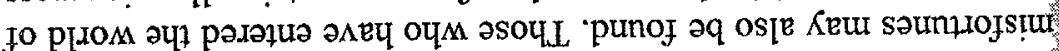

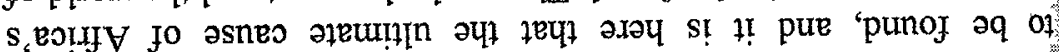

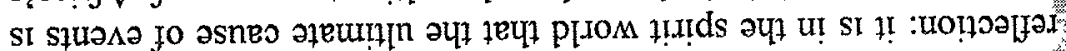

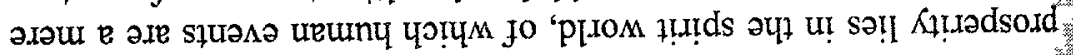

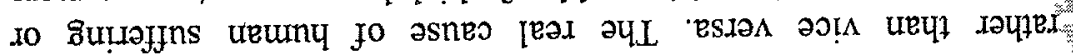

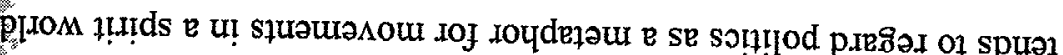

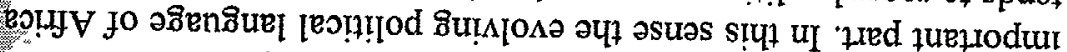

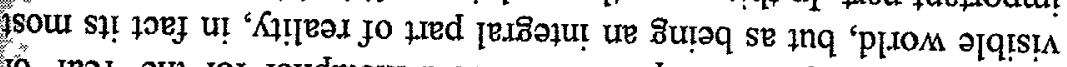

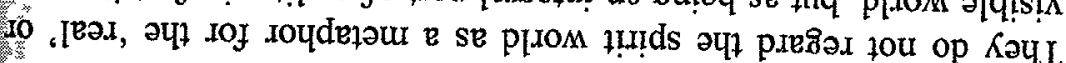

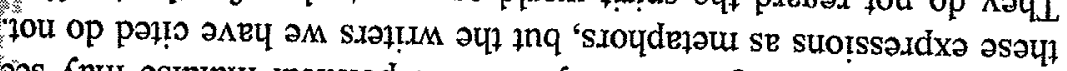

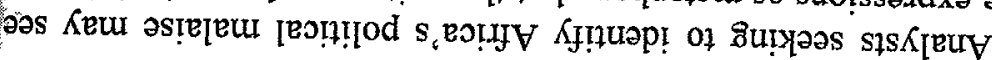

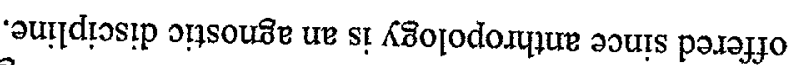

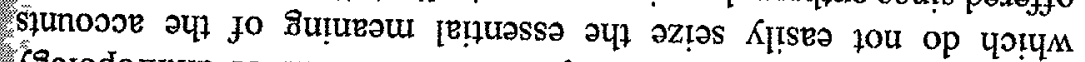

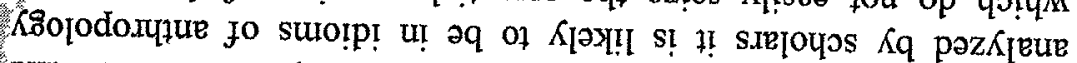

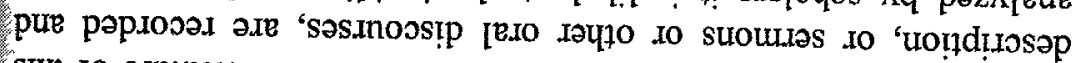

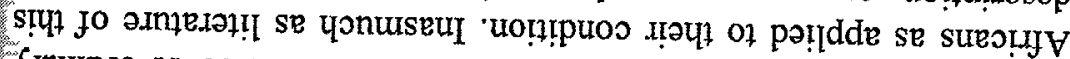

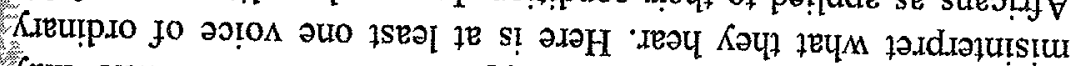

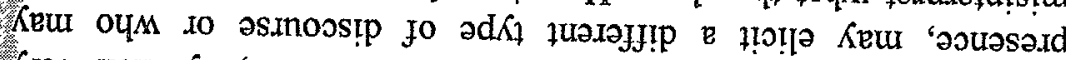

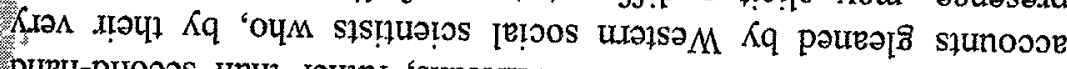

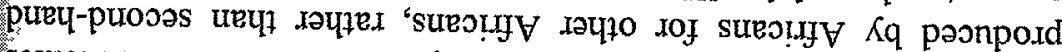

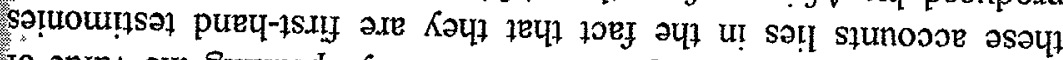

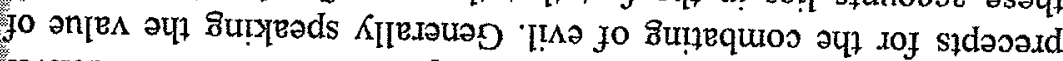

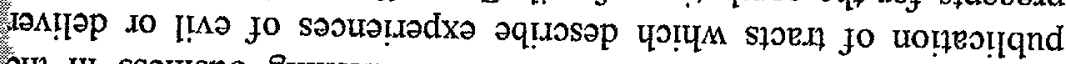

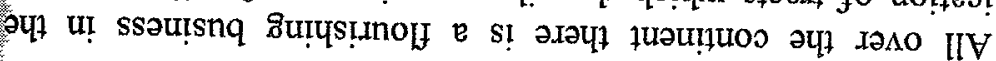

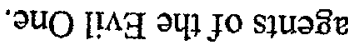

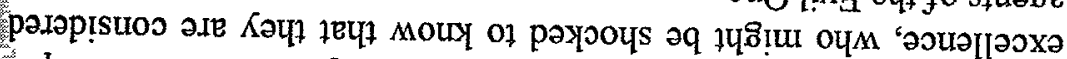

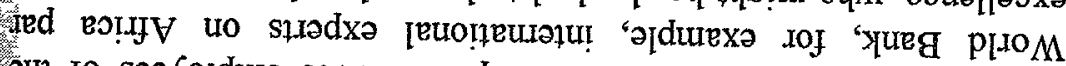

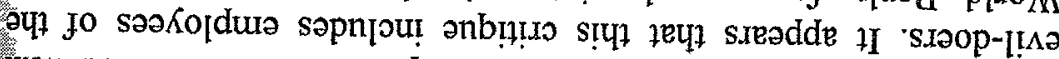

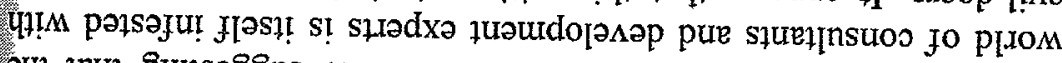

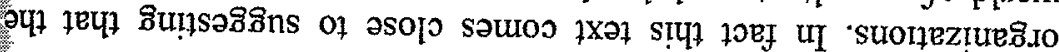

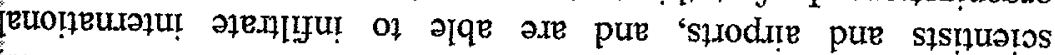

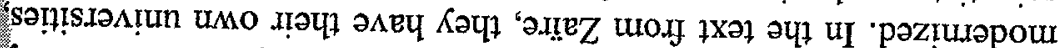

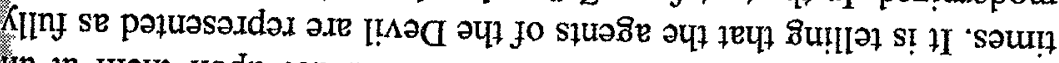

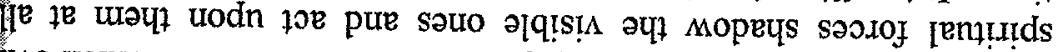
[!

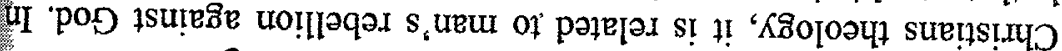
पI "I

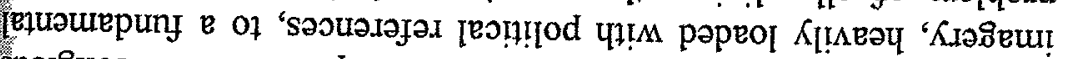

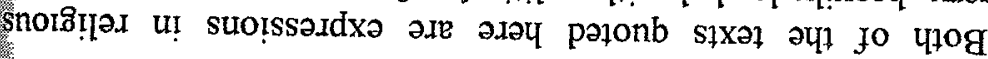

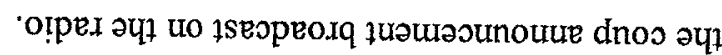

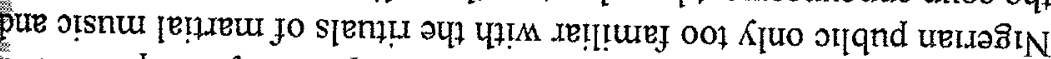

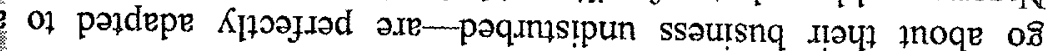

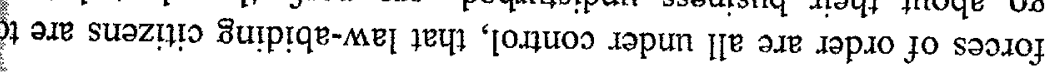




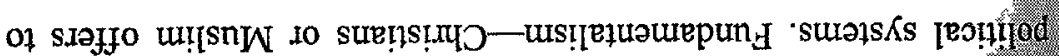

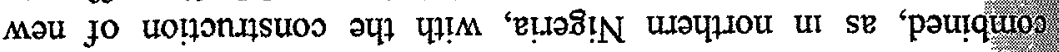

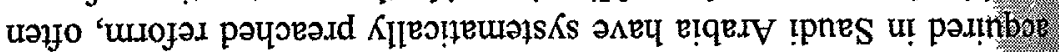

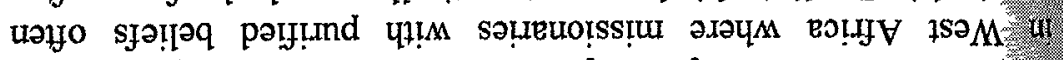

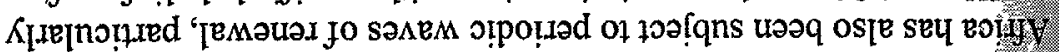

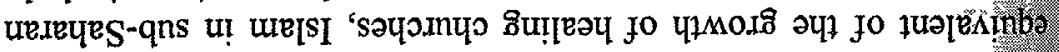

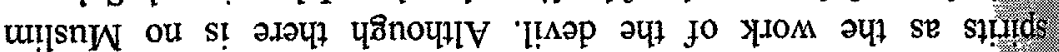

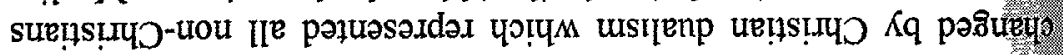

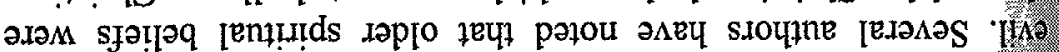

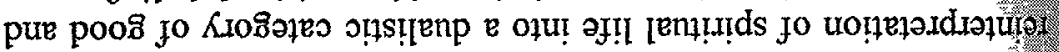
e pure eoufy u! sumstra suəłs

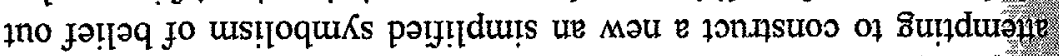

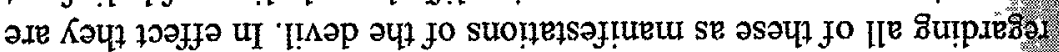

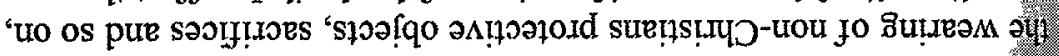

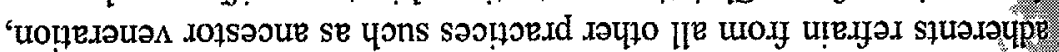

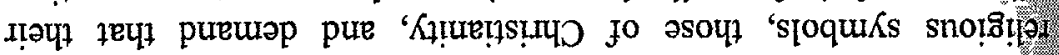

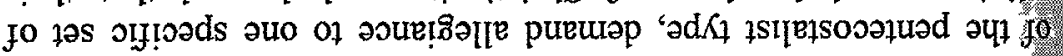

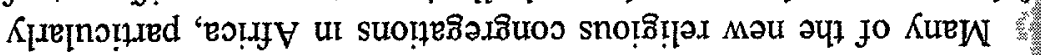

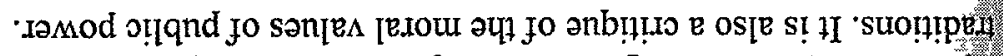

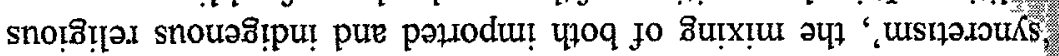

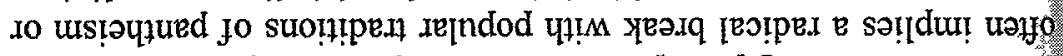

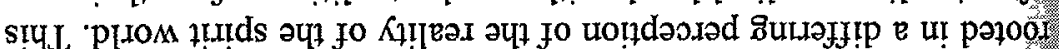

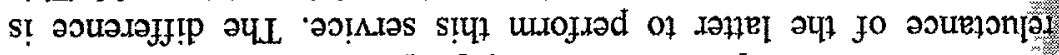

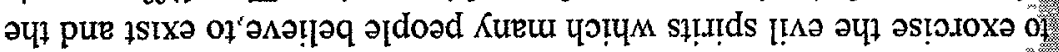

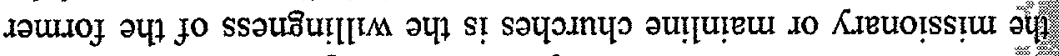

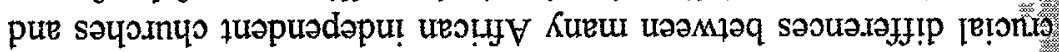

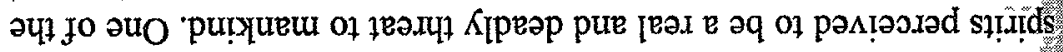

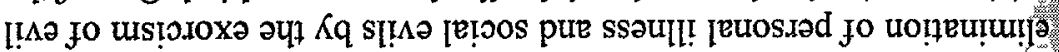

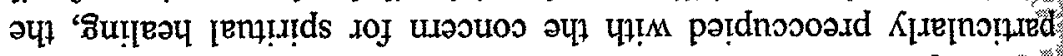

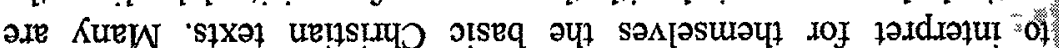

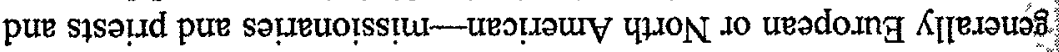

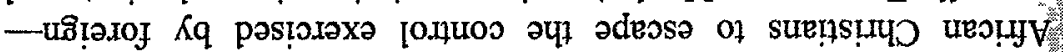

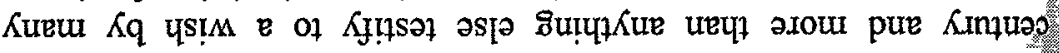

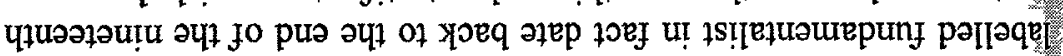

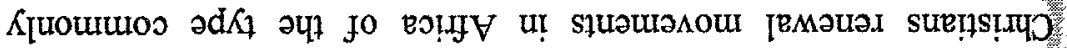

us!̣pequomepun

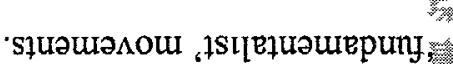

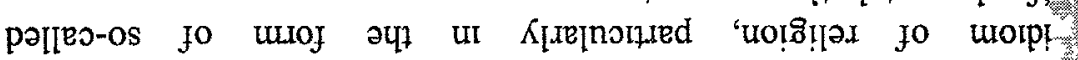

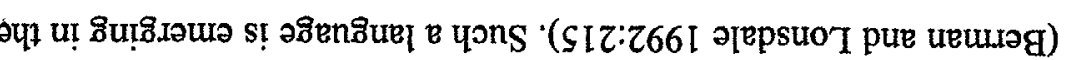

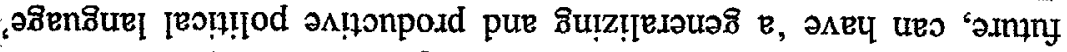

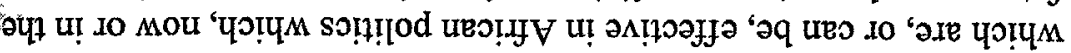
әs.mosstp jo suəzs

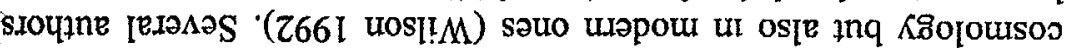

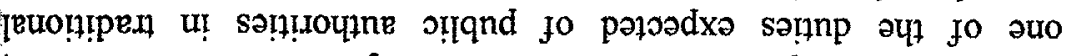

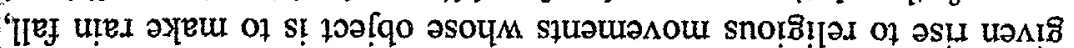

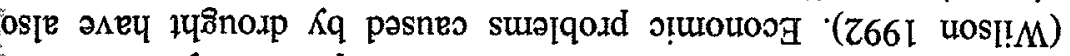

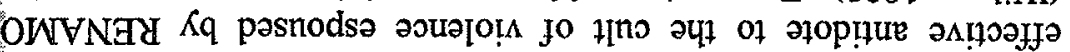

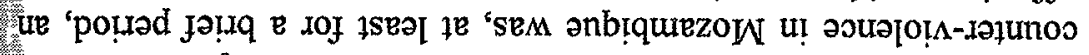

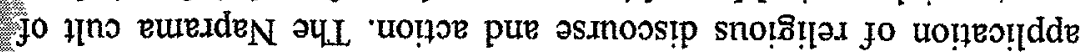

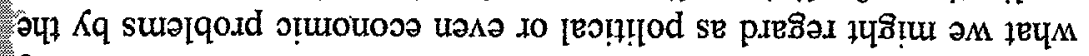

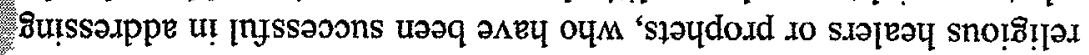

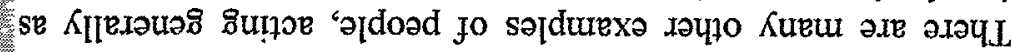

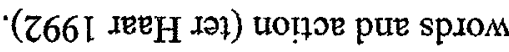

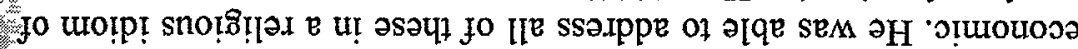

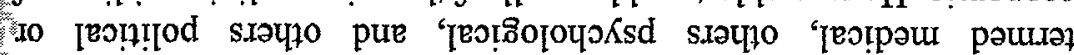

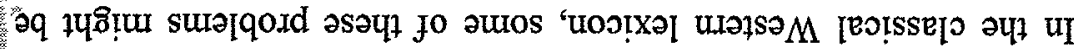

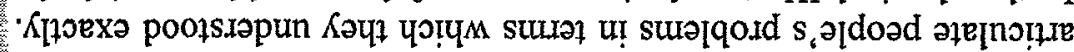
of K!!!

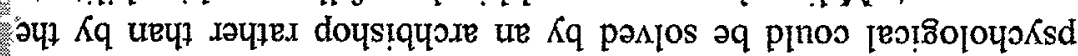

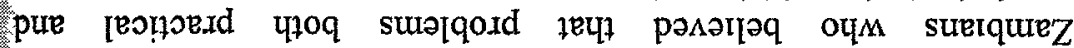

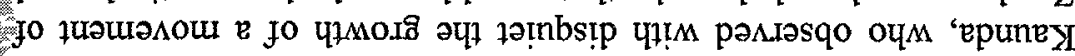

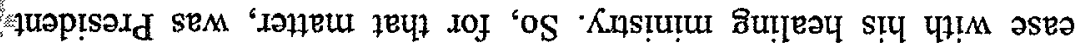

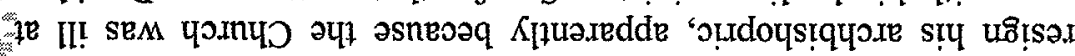
ol parmbar $\kappa$ [I

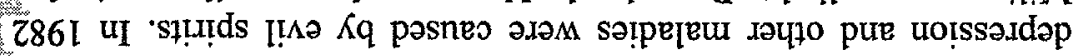

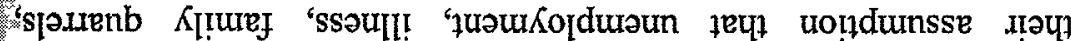

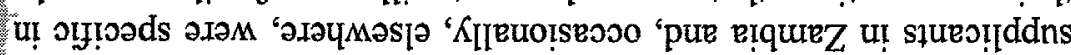

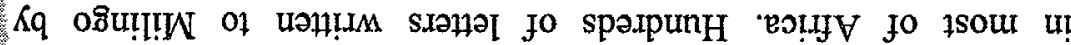

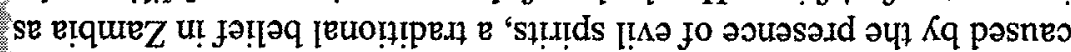

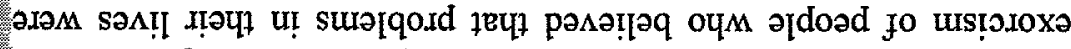

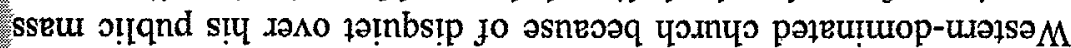

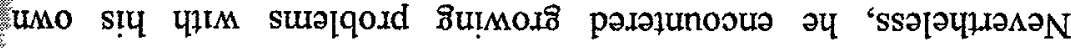

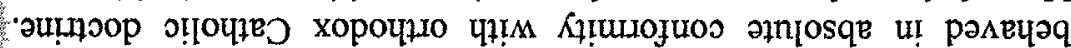

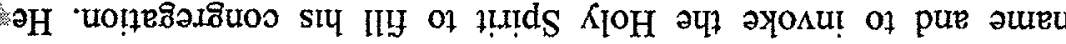
s pọ uा s!l

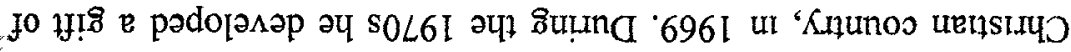




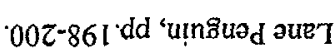

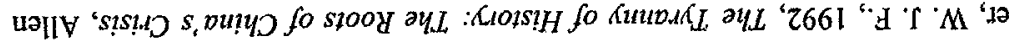
syoog paZ 'uopuot 's.ays!lqn

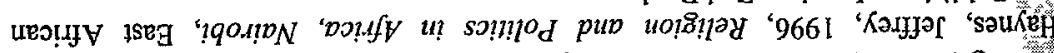

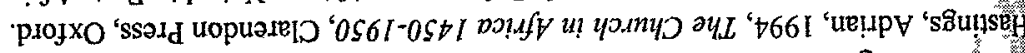
aspiques

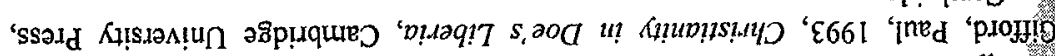

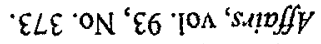

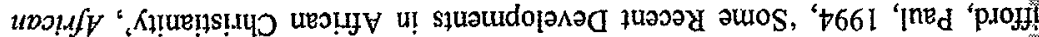

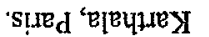

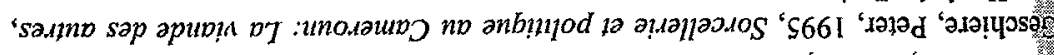

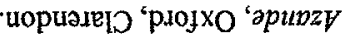

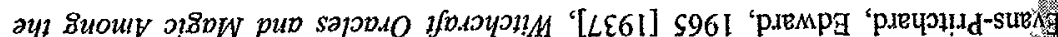

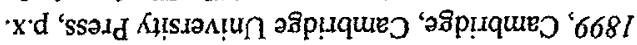

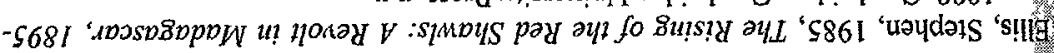

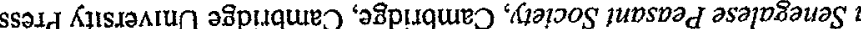

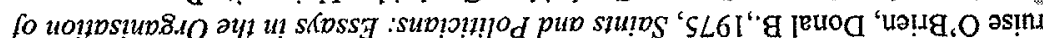

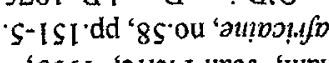

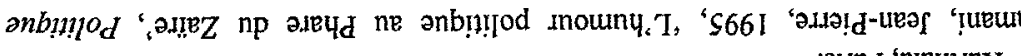

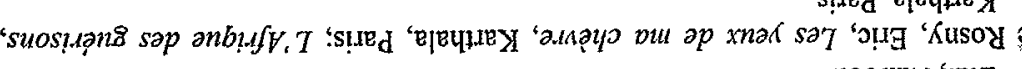

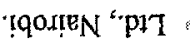

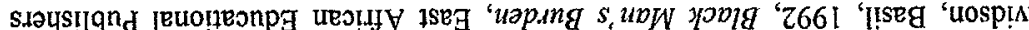

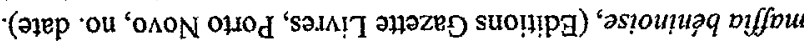

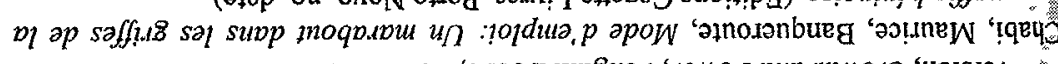

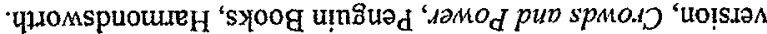

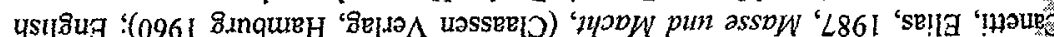
'uopuot 'burquod '

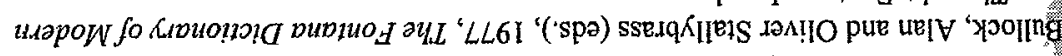

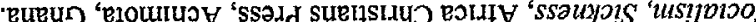

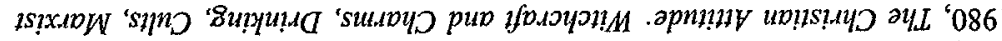

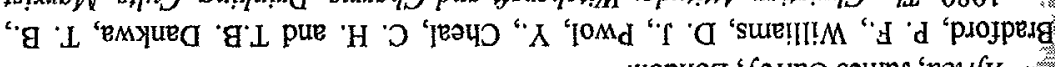
"uopuoT 'Ko.m

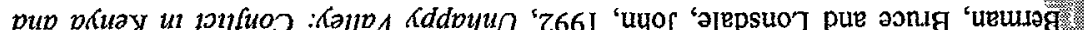

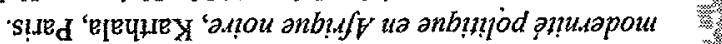

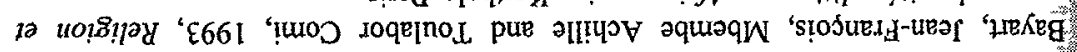
'sure 'sanbulnod saouross sap apeuongeu uoljepuo $0_{d}$ ' $c$ ' ou

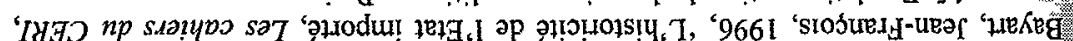
uopuot 'uewsuon

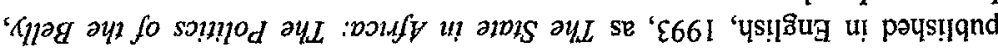

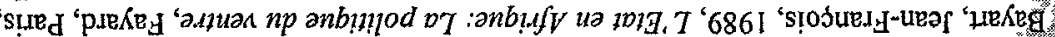
$66-\angle 8 z$ 'dd

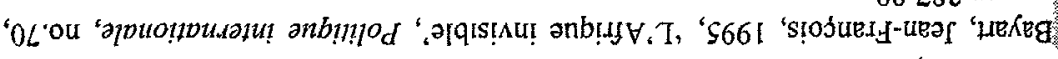
EDOP ' 151.140

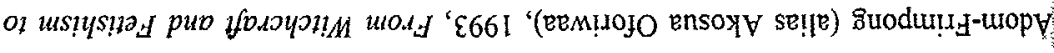
səวนว.ณวృว

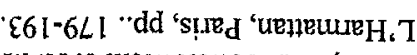

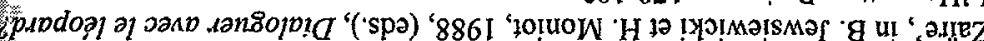

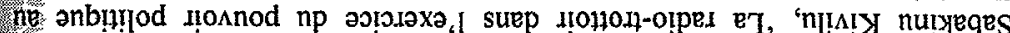

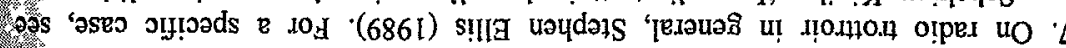

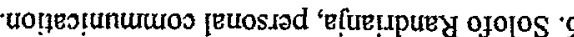

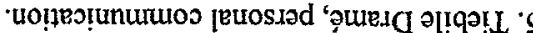
'əu०əج uom!lutyap sịt of

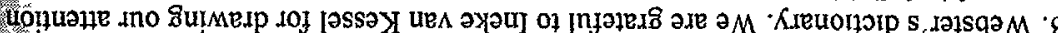

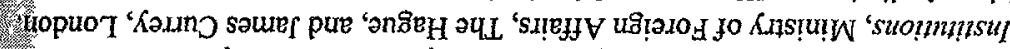

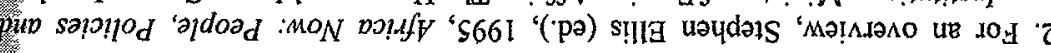

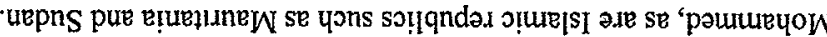

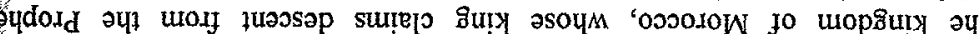

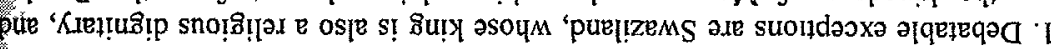
-

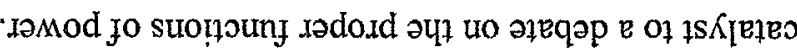

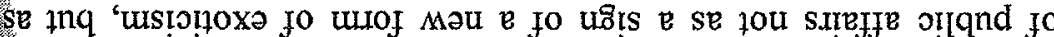

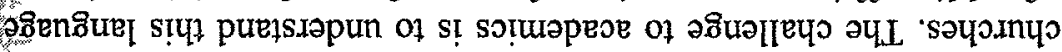

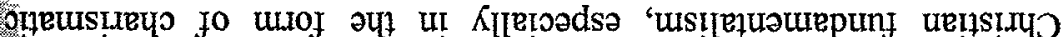

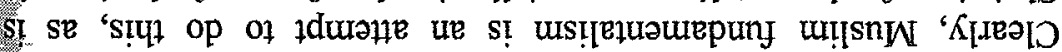

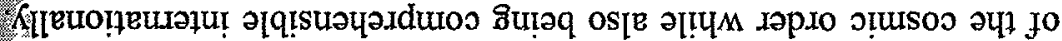

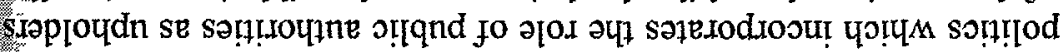

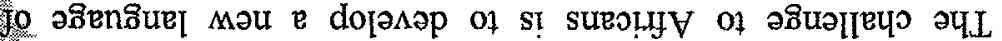
:

IอMod 8ut.xnฺnusas

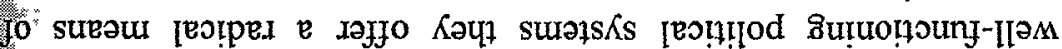

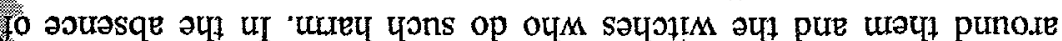

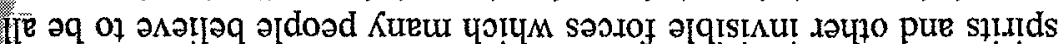

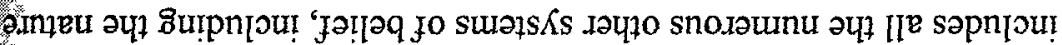

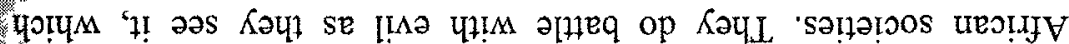

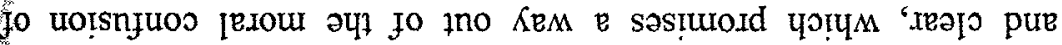

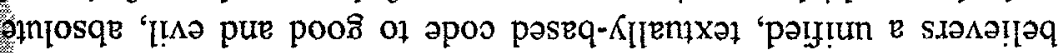


Kaniaki, D. D. and Evangelist Mukend, 1994, Snatched from Satan's Claws: Art Amazing Deliverance by Christ, Enkei Media Services, Nairobi, p.38. Also published in Kiswahili.

Kukah, Matthew Hassan, 1993, Religın, Politics and Power in Northern Nigeria Spectrum Books, Ibadan.

Lan, David, 1985, Guns and Rain: Guerrllas and Spirit Mediums in Zimbabwe, James Currey, London.

Little, Kenneth, 1965, 'The Political Function of the Poro', Africa, XXXV, iv, pp. 349-65, and XXXVI, i 1966, pp. 62-72.

M'Nteba Metena, 'Les conférences nationales afncaines et la figure politique de l'évêque-président', Zaïre, pp.361-72.

Mbembe, Achille, 1988, Les Afriques indociles, Karthala, Paris.

Mbuy, Tatah, H., 1994, Handling Witchcraft-Related Illness, Bamenda.

Nietzsche, F., 'The Will to Power', in The Penguin Dictionary of Political Quotations, Penguin.

Okeke, S. N. I., 1991, Satanic Ministers: The Ministrles of Lucifer, Emabal Company, Isolo, Lagos.

Raison-Jourde, Françoise, 1991, Bible et Pouvoir à Madagascar au XIXe siècle, Karthala, Paris.

Ranger, T. O. and Kimambo 1. N. (eds.), 1972, The Historical Study of African Religions, Heinemann, London, especially the introduction and chapters by B. Ogot, M. Mainga and M. Schoffeleers.

Ranger, Terence, 1986, Religious Movements and Politics in Sub-Saharan Africa', African Studies Review, vol. 29:2, p.1-69..

Roberts, Allen, F., 'L'authenticité, l'aliénation et l'homicide: Une étude sur le processus social dans les zones rurales au Zaïre', in B. Jewsiewicki et H. Moniot, 1988, (eds.), Dialoguer avec le léopard?, l'Harmattan, Paris, pp.xx.

Said, Edward, 1978, W., Orientalism, Kari Publications, Inc., Chıcago.

Stephen Ellis,1989, 'Tuning in to Pavement Radio', Afrcan Affairs, Vol. 88, No.352, pp.321-30.

Ter Haar, Gerrie, 1992, Spirit of Africa: The Healing Ministry of Archbishop Milingo, Africa World Press, Lawrenceville NJ/USA.

Toulabor, Comi, 1986, Le Togo sous Eyadéma, Karthala, Paris.

Tozy, Mohamed, 1995, 'Movements of Religious Renewal', in Stephen Ellis (ed.) Africa Now: People, Institutions and Policies, James Currey, London, pp 58-74.

Wilson, K. B., 1992, 'Cults of violence and counter-violence in Mozambique', Journal of Southern African Studies, XVII, iii.

Wright, Lawrence, 1995, Saints and Sinners, Vintage, New York. 